This item was submitted to Loughborough's Research Repository by the author.

Items in Figshare are protected by copyright, with all rights reserved, unless otherwise indicated.

\title{
Geological carbon sequestration in the context of two-phase flow in porous
} media: a review

\section{PLEASE CITE THE PUBLISHED VERSION}

http://dx.doi.org/10.1080/10643389.2014.924184

\section{PUBLISHER}

(C) Taylor \& Francis

\section{VERSION}

AM (Accepted Manuscript)

\section{LICENCE}

CC BY-NC-ND 4.0

\section{REPOSITORY RECORD}

Abidoye, Luqman K., Diganta Bhusan Das, and Kamal Khudaida. 2014. "Geological Carbon Sequestration in the Context of Two-phase Flow in Porous Media: A Review”. figshare. https://hdl.handle.net/2134/14567. 


\begin{abstract}
Luqman K. Abidoye, Diganta B. Das ${ }^{\#}$, Kamal Khudaida
Department of Chemical Engineering, Loughborough University, Leicestershire, LE11 3TU
\end{abstract}

Revised version submitted for review and publication in:

Critical Reviews in Environmental Science and Technology

Running paper title:

Geological carbon sequestration in the context of two-phase flow

$5^{\text {th }}$ May 2014

${ }^{\#}$ Corresponding Author (Email: d.b.das@lboro.ac.uk' Tel: +44 (0)1509 222509) 
1 Geological carbon sequestration in the context of two-phase flow in porous media: A review

3

4 Luqman K. Abidoye, Diganta B. Das *, Kamal Khudaida

5 Department of Chemical Engineering, Loughborough University, Leicestershire, LE11 $63 T U$

${ }^{\#}$ Corresponding Author (Email: d.b.das@lboro.ac.uk' Tel: +44 (0)1509 222509

\section{Abstract}

In this review, various aspects of geological carbon sequestration are discussed in relation to the principles of two-phase flow in porous media. Literature reports on geological sequestration of $\mathrm{CO}_{2}$ show that the aquifer storage capacity, sealing integrity of the caprock and the in situ processes, e.g., the displacement of brine by supercritical $\mathrm{CO}_{2}\left(\mathrm{scCO}_{2}\right)$, convection-diffusion-dissolution processes involving $\mathrm{scCO}_{2}$ and brine, geochemical reactions, and mineral precipitation depend on the fluid-fluid-rock characteristics as well as the prevailing subsurface conditions. Considering the complexity of the interrelationships among various processes, experimental investigations and network of mathematical functions are required for the ideal choice of geological site with predictable fluid-fluid-rock behaviours that enhance effective monitoring. From a thorough appraisal of the existing publications, recommendations are made for improvement in the existing simulators to fully couple the entire processes involved in the sequestration operations and in situ mechanisms which include injection rate and pressure, brine displacement, simultaneous flow of free and buoyant phases of $\mathrm{CO}_{2}$, various trapping mechanisms, convection-diffusion-dissolution processes, $\mathrm{scCO}_{2}$ brine-rock reactions, precipitation of the rock minerals and the consequences on the hydraulic and hydrogeological properties in the course of time as well as the quantity of injected $\mathrm{CO}_{2}$. Suggestion is made for the inclusion of leakage parameters on sitespecific basis to quantify the risks posed by the prevailing fluid-fluid-rock characteristics as well as their immediate and future tendencies. Calls are also made for thorough investigations of factors that cause non-uniqueness of the two-phase flow behaviour with suggestions for the use of appropriate experimental techniques. The review comprehensively synthesizes the available knowledge in the geological carbon sequestration in a logical sequence. 
Keywords: Carbon sequestration, global warming, capillary pressure, saturation, relative permeability, dynamic effects, modelling and simulation.

\section{Introduction}

40 The world is currently confronted with the issue of global warming arising mainly from 41 the anthropogenic activities, especially man's excessive use of fossil fuels for energy.

42 This has resulted in the unhindered emissions of several climate-unfriendly gases into 43 the atmosphere. There are significant evidence which has shown that these emissions 44 exacerbate the change in the climate by forming a blanket of gases which accumulate 45 at the lower part of the atmosphere, trapping the reflected radiation from the earth 46 thereby raising the surface temperature (Karl et al. 2009; Solomon et al. 2007). Owing 47 to the increasing amount of global emission, carbon dioxide is of serious concern as it is considered to be the greatest culprit in the greenhouse effect (Metz et al. 2005; Marland and Rotty 1984). Sources of these pollutants include, e.g., fossil fuels and deforestation practises (Karl et al. 2009).

51

52 In the face of increasing global energy demands, the desire to mitigate the change in 53 climate presents a daunting and interesting challenge as ninety per cent of world's primary sources of energy still comes from fossil fuels (DOE 2010). The world population still hopes for an improvement in the standard of living, education and health care. These aspirations are directly related to energy consumption. To check the steep rise in carbon emission since the industrial revolution (200 to $\sim 385 \mathrm{ppm}$ ) and preserve

58 the planet, $\mathrm{CO}_{2}$ will need to be reduced to, at most, 350 ppm (Houghton et al. 2001; Hansen et al. 2008). In tackling the challenges, various technologies have emerged while many others are under investigations and implementations to reduce the emissions of these gases into the atmosphere, utilise alternative energies, improve carbon capture, or promote storage efficiencies and so on. Figure 1 shows the pilot and commercial scale carbon sequestration projects being executed worldwide. 


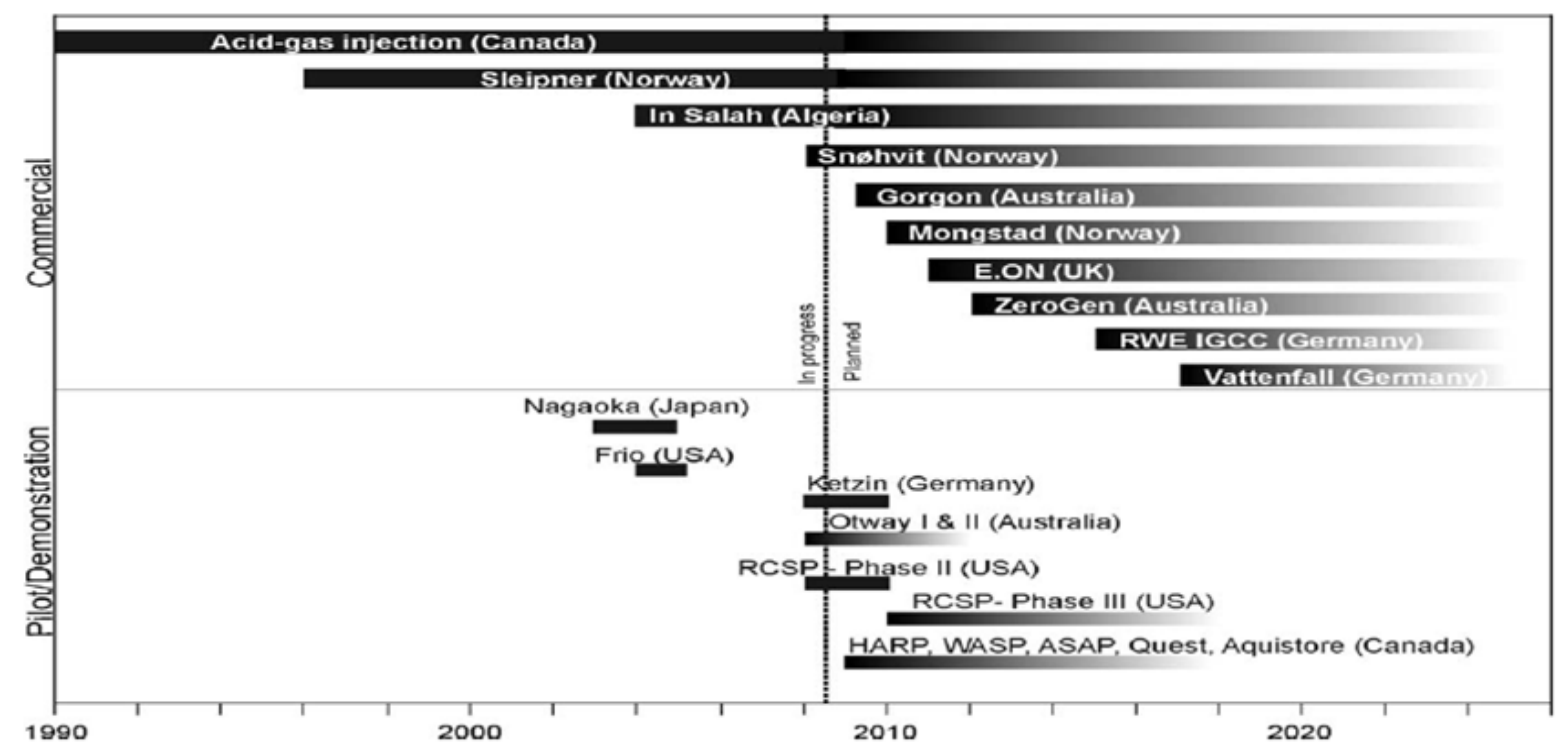

Figure 1: Carbon dioxide sequestration operations at pilot and commercial scales worldwide (Michael et al. 2010).

Popular sites identified as suitable for carbon storage include ocean, brine or saline aquifer, coal bed and depleted oil reservoir. However, the geological sequestration in saline aquifers is considered as the most viable option as it seems to have the largest carbon storage potential (Fujii et al. 2010; Zahid et al. 2011). Parts of the reasons for this choice include the stability, capacity and ubiquity of these aquifers. Stable sedimentary basins are necessary for dependable sequestration activities and such basins are found in most continents (Metz et al. 2005) with estimated capacities of around 1000 to 100,000 gigatonnes of carbon dioxide (Zahid et al. 2011). Researchers have thus dedicated many studies to determine storage capacities and fluid flow mechanisms at prospective sites. The ultimate choice of a particular geological site will depend on a combination of several characteristics which include aquifer size, porosity, permeability, depth, geology, hydrogeology, caprock integrity, petrophysical characteristics, geothermal gradient, proximity to emission sources and existing infrastructures, tectonic stability and faulting intensity (Espinoza et al. 2011).

Scenarios of the injected $\mathrm{CO}_{2}$ in the brine aquifer for sequestration purposes involve several in situ mechanisms, one of which is the displacement of the resident brine by the invading $\mathrm{CO}_{2}$ plume (Zhang et al. 2011; Juanes et al. 2006). Considering this as a kind of two-phase system, multiphase flow researchers have delved into supercritical $\mathrm{CO}_{2}$-brine $\left(\mathrm{scCO}_{2}\right.$-brine $)$ system with emphasis on capillary pressure-saturation-relative permeability relationships $\left(P^{c}-S-K_{r}\right.$ ) (Plug and Bruining 2007; Plug et al. 2006; 
Pentland et al. 2011; Pini et al. 2012; Tokunaga et al. 2013). Capillary pressure and relative permeability for wetting and non-wetting phases are parameters of key importance in modelling the two-phase flow processes encountered during transport of immiscible phases in the underground (Aggelopoulos and Tsakiroglou 2008) and they constitute critical parameters used to history match and design field-scale injection projects using reservoir simulators (Doughty 2007). Many publications are available on the behaviour of $\mathrm{P}^{\mathrm{C}}$-S relationships (Hassanizadeh and Gray 1993; Mirzaei and Das 2007; Nordbotten et al. 2008; Bottero et al. 2011; Goel and O'Carroll 2011; Das et al. 2007) while several others are based on the $\mathrm{K}_{\mathrm{r}} \mathrm{S}$ relationship (Bennion and Bachu 2008; Water et al. 2006; Lenormand et al. 1998; Anderson 1987). Most of these publications consider the cases of oil-water and gas-water systems. So, it will be of specific importance to thoroughly understand how the $P^{c}-S-K_{r}$ relationships behave in $\mathrm{ScCO}_{2}$-brine system.

102

For characterising $\mathrm{scCO}_{2}$-brine system in geological sequestration, two approaches are most commonly considered. Firstly, it involves the use of the theories concerning convection-diffusion-dissolution processes and secondly, it relates to the use of the principles of two-phase flow in porous media. In the first case, the dissolution of the $\mathrm{scCO}_{2}$ in the aquifer brine is considered and it eliminates the need for determination of capillary pressure. In this process, the carbon dioxide-brine solution is defined to be slightly denser than the unsaturated brine causing negative buoyancy by moving to the bottom of the aquifer, enhancing safe and permanent storage, which reduces chances of leakage. The convective process promotes mixing of the brine and $\mathrm{scCO}_{2}$ while enhancing further dissolution of carbon dioxide into the brine (Ozgur and Gumrah 2009).

113 The second approach regards the supercritical carbon dioxide and brine as two 114 immiscible fluid phases, which can be described by $P^{c}-S-K$ r relationships. This assumes that there is a limited dissolution of $\mathrm{CO}_{2}$ in the brine and that displacement process dominates at least for some period after $\mathrm{CO}_{2}$ injection.

118 To consider the $\mathrm{scCO}_{2}$-brine system as a two-phase flow system one requires the 119 understanding of the interactions of the fluid-fluid-porous media (i.e., gas-liquid-solid or $120 \mathrm{scCO}_{2}$-brine-rock) in the system. Analogous to an oil-water system, the immiscible 121 displacement of $\mathrm{scCO}_{2}$-brine/water system may be affected by the presence of heterogeneity in the media, viscosity and density ratios of the two fluids and the 
123 geophysical as well as the geochemical conditions of the domain. For example, media

124 heterogeneities affect the $\mathrm{P}^{\mathrm{c}}-\mathrm{S}$ and $\mathrm{K}_{\mathrm{r}} \mathrm{S}$ profiles (Das et al., 2004; Aggelopoulos and 125 Tsakiroglou 2008; Mirzaei and Das, 2013; Khudaida and Das, 2014) while they also 126 raise the value of the irreducible wetting phase saturation (Das et al. 2006). In addition, 127 the heterogeneity (e.g., fractures) may create preferential flow path which increases the 128 effective permeability of the fluid (Aggelopoulos and Tsakiroglou 2008). The 129 permeability to fluid is also affected by the presence of micron-scale heterogeneity (e.g., 130 lamina) where varying intrinsic permeability value the degree of heterogeneity affect the 131 average permeability of the domain (Alabi 2011). These scenarios are important in the 132 choice of geo-sequestration sites as they affect storage capacity of the aquifer and can 133 influence the risks of leakage.

135 Recent review papers on $\mathrm{CO}_{2}$ sequestration consider the alternative sequestration in limestone (Stanmore and Gilot 2005), technologies and costs (Abu-Khader 2006), health and safety issues (Zakkour and Haines 2007), analogy between traditional liquid waste disposal and carbon storage (Tsang et al. 2007), storage in marine environment (Huh et al. 2009), pilot projects (Michael et al. 2010), $\mathrm{scCO}_{2}$-brine relative permeability experiments (Müller 2011), caprock integrity (Shukla et al. 2010) and present and future challenges (Zahid et al. 2011). Shukla et al. (2010) acknowledge the influences of the fluid-fluid-media characteristics of the $\mathrm{scCO}_{2}$-brine system on trapping mechanisms, breakthrough of the injected fluid and capillary sealing of the caprock. Also, Müller

144 (2011) notes that while there are similarities in the measurement of relative permeability for oil-water and $\mathrm{CO}_{2}$-water systems, exception exists in the reactivity of core materials with $\mathrm{CO}_{2}$, resulting in permeability, porosity and wettability alteration. These pointed to the unique characteristics of the two-phase flow parameters in the geological sequestration processes. However, Shukla et al. (2010) are primarily concerned about caprock integrity while Müller (2011) investigates the relative permeability experimental methods.

To reliably predict $\mathrm{CO}_{2}$ storage phenomena, understanding the capillary behaviour of 153 supercritical $\mathrm{CO}_{2}$ and its dependence on water saturation are essential (Tokunaga et al. 154 2013). Characterising a system for geological storage of $\mathrm{CO}_{2}$ also comes with the 155 challenges of dealing with high gas pressure and temperature above ambient conditions as $\mathrm{CO}_{2}$ is stored at a depth of around $1 \mathrm{~km}$ or more from earth's surface 157 (Rutqvist 2011). In addition to changing property of $\mathrm{CO}_{2}$ at slight variation of conditions 
158 in the subsurface, these scenarios might cause non-uniqueness in the functional 159 representation of the system such as those discussed by Das et al. (2006).

161 The above discussions introduce the practices of geological sequestration and the relevance of two-phase flow ( $\mathrm{scCO}_{2}$-brine) parameters. It is however equally important 163 to illustrate the challenges and trends found in the literature concerning the 164 determination, application and interpretation of relevant two-phase flow parameters in 165 relation to the carbon sequestration processes. In addressing these issues, this review intends to examine the research activities relating to geological sequestration of $\mathrm{CO}_{2}$ together with the issues involved in the determination of two-phase relationships for $\mathrm{scCO}_{2}$-brine system from experiments, modelling and simulations. How $\mathrm{ScCO}_{2}$-brinerock characteristics affect stability/instability of the system will be extensively discussed and suggestions as well as recommendations will be made in view of the identified gaps in knowledge. This work is based on the up-to-date reliable information available

172 in the open literature

\section{Characteristics of the geological sites}

175 Geological sites hold the important properties that determine a successful geological $176 \mathrm{CO}_{2}$ sequestration projects. In this regards, the geological media should meet some 177 fundamental conditions to ensure successful storage of carbon dioxide. Three of these 178 are capacity, injectivity and confinement (Gunter et al. 2009). Studying and modelling $179 \mathrm{CO}_{2}$ sequestration in geological formation need a clear understanding of multi-phase 180 flow characteristics and their behaviour in porous media. The above-mentioned 181 parameters (i.e., aquifer capacity, injectivity and confinement) bear relation to media 182 properties i.e., porosity, tortuosity, permeability, relative permeability, dispersion 183 coefficient, capillarity, connectivity, adsorption and wettability as well as to two-phase 184 flow characteristics in the medium. Some of these media properties in the context of the 185 studies on $\mathrm{CO}_{2}$ sequestration are discussed below.

\section{$187 \quad 2.1 \quad$ Porosity and pore size distribution}

188 In their review of characteristics of potential geological formations for $\mathrm{CO}_{2}$ sequestration, 189 Kopp et al. (2009) explain that geological formations are suitable for carbon dioxide 190 storage if they demonstrate high values of porosity and permeability. These are crucial 191 for storage of high amounts of carbon dioxide and allow its injection to be done 192 economically. 
194 Porosity is the fraction of the aquifer that is composed of voids (Bear 2013). The 195 interconnected voids in the aquifer forms what is referred to as the effective porosity and it determines the effective storage capacity of the aquifer. Chadwick et al. (2008) suggest that the amount of $\mathrm{CO}_{2}$ that can be stored in a given saline aquifer in terms of a capacity factor $\mathrm{C}$ is:

Where $\mathrm{C}^{\text {gas }}=\left\langle\phi \cdot \mathrm{S}_{\mathrm{g}}\right\rangle, \mathrm{C}^{\text {liquid }}=\left\langle\phi . S_{1} \mathrm{X}_{1}^{\mathrm{CO}_{2}} \cdot \rho_{1} / \rho_{\mathrm{g}}\right\rangle$ and $\mathrm{C}$ is the volume fraction of the reservoir available for storage. $\mathrm{C}$ is taken as the sum of the free supercritical $\mathrm{CO}_{2}\left(\mathrm{C}^{\text {gas }}\right)$ and $\mathrm{CO}_{2}$ dissolved in the brine ( $\mathrm{C}^{\text {liquid}}$ ). $\phi$ is the effective domain porosity and, $\mathrm{S}_{\mathrm{l}}$ and $\mathrm{S}_{\mathrm{g}}$ are the fractional volumes of the pore space containing liquid and $\mathrm{scCO}_{2}$ phases, respectively. $X_{1}^{\mathrm{CO}_{2}}$ refers to the mass fraction of dissolved $\mathrm{CO}_{2}$ in the brine, $\rho_{\mathrm{g}}$ and $\rho_{\mathrm{I}}$ are the densities of the $\mathrm{scCO}_{2}$ and liquid phases, respectively. The angle brackets imply averaging over the spatial domain of storage. Equation 1 shows that the porosity, $\phi$, plays a very important role in determining the capacity factor of an aquifer and it can serve as a factor to check suitability of an aquifer for storage. According to Espinoza et al. (2011), the volume of $\mathrm{CO}_{2}$ injected, $\mathrm{V}_{\mathrm{CO}_{2}}$, in an aquifer is a function of average 212 aquifer porosity as follows:

$$
\mathrm{V}_{\text {bulk }}=\frac{\mathrm{V}_{\mathrm{CO}_{2}}}{\phi} \frac{1}{\psi}
$$

Where $\Psi$ is a water or brine displacement efficiency coefficient and it is a function of 217 the media and process characteristics. In essence, the effective porosity of an aquifer 218 is a key factor in its capacity to store $\mathrm{CO}_{2}$. According to Chadwick et al. (2008) a 219 porosity greater than $20 \%$ is a positive indicator in a site selection while a value lesser 220 than $10 \%$ porosity calls for caution. The porosity of sediment tends to decrease with depth as the effective stress on the sediment increases. The pore size and structure of an aquifer tend to change under the same influence as the pore size is a function of porosity and specific surface. Also, due to enormous complexity of the pore structure

224 of any porous media in terms of the number of pores, their size, shape, orientation, and manner of interconnection of the pores, it often becomes important to consider 
226 the pore size distributions of an aquifer. The pore size distribution is defined as a

227 fraction, $\mathrm{f}$, of total pore spaces within a range of pore diameter $\delta$ and $\delta+\mathrm{d} \delta$ as 228 expressed in the following distribution function:

$229 \int_{0}^{\infty} f(\delta) d \delta=1$

$230 \quad(3)$

231

232 Information concerning the pore size distribution of a particular aquifer can be 233 obtained from analysis of core measurements and even geophysical logs of adjacent wells. In such sample, the $\mathrm{P}^{\mathrm{C}}$ required to force a liquid (e.g., mercury) into the pores can be used to approximate $\delta$, with the following equation (Bear 2013):

236

$\delta=4 \gamma \cos \theta / P^{c}$

238

(4)

239

where, $\gamma$ is the interfacial tension between the two fluids and $\theta$ is the contact angle.

Pore size distributions are useful in the analysis of permeability reduction, e.g., as a

result of clay swelling, microbial growth in pores, mineral precipitation, etc., (Tiab and Donaldson 2004). Theory for the penetration of non-wetting fluid into the pore was developed by Ritter and Drake (1945) while Burdine et al. (1950) applied it to study two-phase flow in reservoir rocks. In the absence of typical mercury injection information, pore size distribution information can be obtained from measurements made by porous semi-permeable diaphragm method (Burdine 1953). Other methods for determining pore size distribution, e.g., adsorption isotherm (Dollimore and Heal 1964; Seaton and Walton 1989) and induced polarization logging measurements (Vinegar and Waxman 1987) have been reported as well. Information on pore size distribution is important in the characterization of the displacement of brine by $\mathrm{scCO}_{2}$ in the saline aquifer as it can be used to calculate the relative permeability of the phases (Burdine 1953).

Changing porosity, mineral precipitation, dissolution and change in effective stress are some of the factors that result in the evolution of pore size distributions of a reservoir. Mineral precipitation in the porous media is often affected by pore size (Emmanuel et al. 2010) and vice versa. While the large pores permit ready precipitation of minerals, the smaller pores might inhibit the process leading to reduced bulk reaction rate, 
260 which in effect stabilises the porosity. Also, geochemical reaction with rock minerals is

261 considered to be one of the trapping mechanisms for long term sequestration. The 262 pore lengths and their distribution might affect how readily the reactions occur at different parts of the sediment. Precipitation of quartz was found to be inhibited in pores smaller than $10 \mu \mathrm{m}$ in diameter. Also, the pore size distribution will also affect the dissolution rate which is another mechanism identified for trapping as varying solubility is applicable (Emmanuel et al. 2010). In addition, the standard deviation of pore size distribution affects $\mathrm{CO}_{2}$ breakthrough into a medium (Espinoza et al. 2011).

\subsection{Intrinsic, Relative and Effective Permeability}

270 Permeability, as the name suggests, is an indication of how easily a fluid will pass through a porous medium. It can be defined by Darcy's law (Bear 2013; Virnovsky et al. 1995) for an incompressible fluid having viscosity, $\mu$, which flows through a porous medium with length, L, and cross sectional area, $\mathrm{A}$, at flow rate, $\mathrm{q}$, and pressure difference of $\Delta \mathrm{P}$ across the domain. The isotropic permeability, $\mathrm{K}$, of the porous medium is defined as:

$277 \quad K=\frac{q \mu L}{A \triangle P}$

Its value is dependent on the porous structure of the medium. Appropriate permeability needs to be maintained in the medium to ensure effective storage of $\mathrm{CO}_{2}$ (Rutqvist 2012). However, the permeability of a medium is affected by the reactions, dissolution and precipitations of the rock minerals. Simulations have shown that following $\mathrm{CO}_{2}$ injection, dissolution of carbonate cement initially increases the sediment porosity but subsequent reactions result in dissolution of feldspar and precipitation of carbonate minerals and clay leading to reduction in permeability and porosity (Gaus et al. 2005). This implies that the original permeability of the sediment may alter in the course of injection and will affect the prediction of the process behaviour.

Meanwhile, the flow processes (like that in geological sequestration system) can hardly occur with a single fluid. This reality leads to the concept of relative permeability that represents the two-phase relationships of $\mathrm{scCO}_{2}$-brine system in a geological media. While the permeability is the intrinsic property of the medium, relative permeability is 
294 the characteristic of the fluid-fluid-solid system and it comes to play when two or more 295 fluids are present in the porous medium. The term describes the extent to which one fluid is hindered by the other. Though relative permeability is dependent on a number of factors, available experimental evidence indicates the concept of relative permeability that depends on only saturation is a good approximation for all practical purposes (Bear 2013). It is expressed through Darcy's law set up for individual phase $i$ that flows in the pore space:

301

302

$$
\mathrm{q}_{\mathrm{i}}=\left(\frac{\mathrm{KK}}{\mu_{\mathrm{ri}}}\right) \mathrm{A} \frac{\Delta \mathrm{P}_{\mathrm{i}}}{\Delta \mathrm{x}}
$$

$\mathrm{q}_{\mathrm{i}}, \mathrm{K}_{\mathrm{ri}}, \mu_{\mathrm{i}}$, and $\Delta \mathrm{P}_{\mathrm{i}}$ refer to the flow rate, relative permeability, viscosity and the pressure drop, respectively for phase i. The ratio $\left(\frac{K_{\mathrm{ri}}}{\mu_{\mathrm{i}}}\right)$ denotes the "mobility" of phase $\mathrm{i}$.

Figure 2 shows the relative permeability plots of $\mathrm{CO}_{2}$-water system. It consists of 308 primary, secondary and tertiary drainage of the system (see, Bear (2013) for definitions of these processes). It can be seen that following primary drainage, the residual water saturation continues to decrease in subsequent drainages. This is attributed to dissolution property of $\mathrm{CO}_{2}$ in water and a contrast was shown in $\mathrm{N}_{2}$-water system which shows a fairly similar residual saturation for the subsequent drainages owing to lesser solubility of $\mathrm{N}_{2}$ (Pistone et al. 2011). Water relative permeability, $\mathrm{K}_{\mathrm{rw}}$ is higher for larger portion of the water saturation though the value reduces with subsequent drainages while that of $\mathrm{CO}_{2}$ remains low. Relative permeability of $\mathrm{CO}_{2}, \mathrm{~K}_{\mathrm{rg}}$, remains low owing to dissolution and diffusion into smallest pore spaces with no need to overcome the entry pressure. Evolution of $\mathrm{CO}_{2}$ from this dissolution state displaces previously immobile water which further impedes $\mathrm{CO}_{2}$ mobility (Pistone et al. 2011). Thus, the residual saturation of water continues to reduce following subsequent drainage.

321 Bickle et al. (2007) concluded that the relative permeability-residual saturation relations have a great influence on average carbon dioxide saturation as well as plume evolution velocity and as such, have a great effect on storage capacity. Hysteresis in relative permeability has the tendency to enhance residual trapping. This is defined, for a particular $\mathrm{CO}_{2}$ saturation, as a reduction in relative permeability during imbibition 
compared to drainage (Chadwick et al. 2008). Strong hysteresis in relative permeability results in 'sticky' plumes that leave behind relatively higher amounts of $\mathrm{CO}_{2}$ trapped compared to weak hysteresis leaving behind small amount. This scenario was observed in the simulation of sequestration project at Sleipner (Norway) (Chadwick et al. 2008).

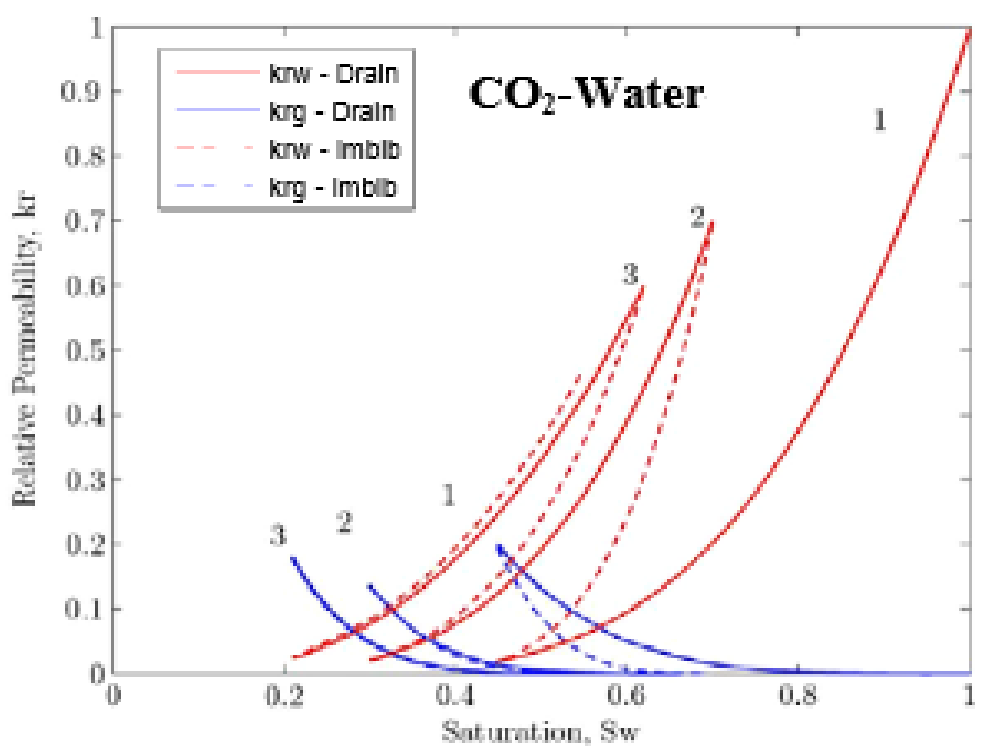

Figure 2: Relative permeability curves for $\mathrm{CO}_{2}$ (blue) and water (red) (Pistone et al. 2011).

On the basis of a large number of drainage experiments with various types of media, Brooks and Corey (1964) suggest the following relative permeability function:

$$
\mathrm{k}_{\mathrm{rw}}=\left(\mathrm{S}_{\mathrm{e}}\right)^{(2+3 \lambda) / \lambda}=\left(\frac{\mathrm{P}_{\mathrm{b}}}{\mathrm{P}^{\mathrm{c}}}\right)^{(2+3 \lambda)} \quad \mathrm{P}^{\mathrm{c}} \geq \mathrm{P}_{\mathrm{b}}
$$

$\mathrm{k}_{\mathrm{rnw}}=\left(1-\mathrm{S}_{\mathrm{e}}\right)^{2}\left(1-\mathrm{S}_{\mathrm{e}}^{(2+\lambda) / \lambda}\right)=\left[1-\left(\mathrm{P}_{\mathrm{b}} / \mathrm{P}^{\mathrm{c}}\right)^{\lambda}\right]^{2}\left[1-\left(\mathrm{P}_{\mathrm{b}} / \mathrm{P}^{\mathrm{c}}\right)^{2+\lambda}\right]$

342 where $\lambda$ is the pore-size distribution index, $\mathrm{P}_{\mathrm{b}}$ is referred to as the bubbling or threshold 343 pressure or entry pressure. $S_{e}$ is the effective saturation and can be expressed as $344 S_{e}=\left(P_{b} / P^{c}\right)^{\lambda}$ for $P^{c} \geq P_{b}$. Even though the above results are deduced for isotropic 345 media, their validity makes them applicable to a wide range of pore-size distributions 346 (Bear 2013). Several factors can affect the effective permeability of an aquifer. Pore 347 size distributions, media heterogeneities and scale can be of considerable impact. This 
348 was corroborated by Alabi (2011) investigating the difference in the flow rate of fluid in 349 homogeneous media and different types of heterogeneous media. The author found out 350 that the permeabilities of heterogeneous media are lower than the permeabilities of 351 homogeneous media and that mixed heterogeneity has higher permeability than 352 layered type. This implies that fluid flows faster in mixed heterogeneous sample than 353 the layered type.

354

\section{$355 \quad 2.3 \quad$ Threshold pressure (bubbling pressure)}

356 In $\mathrm{scCO}_{2}$-brine system, the pressure in the invading fluid (i.e., $\mathrm{scCO}_{2}$ ) at the interface 357 between fluid-fluid and rock system is required to exceed the minimum entry pressure 358 of the sediment. This implies a certain pressure must be reached in the non-wetting 359 fluid before it begins to penetrate the sample, displacing the wetting fluid contained in it 360 (Bear 2013). The minimum pressure needed to initiate this displacement is called the threshold pressure (or bubbling pressure) or non-wetting fluid entry value or breakthrough pressure. This parameter is also a pointer to injectivity of a medium and its excessive magnitude can pose serious risk to the caprock.

Understanding of the threshold pressure of a caprock saturated with water is important 366 when a gas is to be stored in the reservoir underneath the caprock. This is also the breakthrough pressure when $\mathrm{CO}_{2}$ can enter through the caprock. Its value depends on the mean pore size related to specific surface $S_{s}$, standard deviation in pore size distribution and void ratio e as well as the wettability of the minerals in the presence of water and $\mathrm{CO}_{2}$ (Espinoza et al. 2011); $\mathrm{e}=\mathrm{e}_{1 \mathrm{kPa}}-\mathrm{C}_{\mathrm{c}} \log \left(\mathrm{p}^{\prime} / 1 \mathrm{kPa}\right)$ where $\mathrm{p}^{\prime}$ is the in situ effective stress and $\mathrm{e}_{1 \mathrm{kPa}}$ is the critical state void ratio when the mean confining stress is $1 \mathrm{kPa}$. Espinoza and Santamarina (2010) gave expression for breakthrough pressure, $\mathrm{P}_{\text {thru }}^{\star}$, by extension of Laplace's capillary pressure equation:

$375 \mathrm{P}_{\text {thru }}^{*}=\Psi \frac{\mathrm{S}_{\mathrm{s}} \rho \gamma \cos \theta}{\mathrm{e}}$

$\Psi$ is a factor that depends on the clay fabric and grain size distribution and a value of $3790.04<\psi<0.08$ applies to smectite clay barriers and, $\gamma$ is the interfacial tension. This interfacial tension is an important property of the two-phase system. Its influence 
381 depends on the prevailing conditions, e.g., temperature, pressure, salinity and cation 382 valence. Detail discussions and the implication of these factors on $\gamma$ will be found 383 under subsection 5.2 in this work.

384

385 386

387

388

389

390

391 392 393 394 395 396 397

398 399 400 401 402 403 404 405 406 407 408 409 410 411 412

Aside the sediment where actual injection and storage occur, threshold capillary pressure is an important parameter of the caprock that gives indication about its sealing capacity or integrity of caprock. It combines with caprock permeability to determine possibility of leakage and its rate of occurrence (Fleury et al. 2010; Pusch et al. 2010). Thus, the threshold pressure for the sediment must be well below that of the caprock to avoid undue development. Also, since the injection and the in situ displacement processes result in pressure fluctuations within the system, the caprock entry pressure should be well in excess of any possible pressure increase for long-term safety. Practical caprock core from Sleipner (Norway) was reported to possess greater than 3.3 MPa capillary entry pressure to $\mathrm{scCO}_{2}$ while that of another project from Schwarze Pumpe (Schweinrich) is predicted to be in the range 4 to $40 \mathrm{MPa}$ (Chadwick et al. 2008).

\subsection{Wettability}

Wettability is the ability of a liquid to adhere to a solid surface due to their intermolecular interactions. It has a significant impact on the relative permeabilitysaturation relationships and can be determined from the combination of cohesion forces, which cause the drop to prevent contact with the solid surface, and adhesion forces that try to spread the liquid across the solid surface in a flow system. It is among the factors that determine the entry pressure of the geological media (Espinoza et al. 2011). If the medium is $\mathrm{CO}_{2}$-wet, it becomes easier for the invading $\mathrm{CO}_{2}$ to displace the resident brine. However, if the medium is water-wet, then higher entry pressure is required for the invading $\mathrm{CO}_{2}$ to penetrate the medium. Publications on water-wet, $\mathrm{CO}_{2}$-wet and mixed-wet media have been reported. In relation to carbon geological sequestration, many of the representative media samples, quartz, calcite, kaolinite, microcline and illite were reported to be water-wetting (Wang et al. 2012). The possibility of the alteration in wettability based on saturation history of the medium was also reported (Plug et al. 2006). 


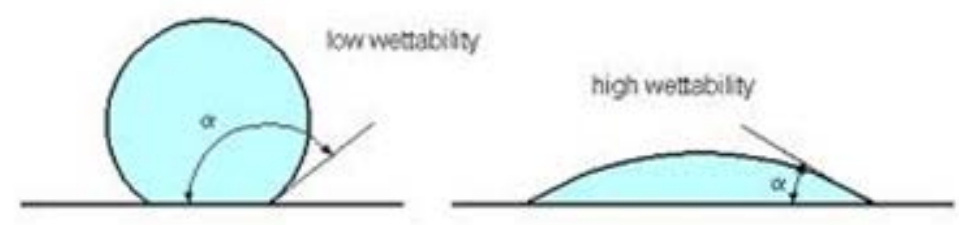

414 Figure 3: Wettability index of liquid as a function of contact angle $(\alpha)$ : $\alpha>90^{\circ}$ (non415 wetting liquid), $\alpha<90^{\circ}$ (wetting liquid). The possibility of $\alpha=0^{\circ}$ (perfectly wetting) is not 416 shown.

418 Wettability is related to capillary effects and occurs at different degrees according to the 419 angle at which fluid1-fluid2 interface meets with the fluid1-solid interface. This contact 420 angle provides an inverse measure of wettability (Shafrin and Zisman 1960).

421 Importance of wettability in the determination of $\mathrm{P}^{\mathrm{C}}-\mathrm{S}-\mathrm{K}_{\mathrm{r}}$ relationships is great and 422 the in situ alteration in wettability can lead to error in calculation and predictions if not 423 considered. Wettability indices (e.g., USBM index, Ammott index and Hammervold424 Longeron ( $\mathrm{HL}$ ) index) are employed in quantifying wettability and its changes for the 425 drainage and waterflooding processes in the porous media using the $P^{\mathrm{C}}$-S curves 426 (Pentland 2011). Table 1 shows the wettability indices for oil-water system.

428 Table 1: Wettability indices for oil-water indices (Pentland 2011)

Index Water-wet Neutrally-wet

Oil-wet

\begin{tabular}{lrrr}
\hline Ammot & Positive & 0 & 0 \\
(displacement by water ratio) & & & \\
Hammervold-Longeron & 1 & 0 & -1 \\
USBM & & near 1 & near 0 \\
near -1 & & & \\
\hline
\end{tabular}

430 By implication, partial-wetting behaviour of $\mathrm{CO}_{2}$ (e.g., limestone rock under reservoir 431 condition) results in lower capillary pressure and higher mobility for brine and can lead 432 into lower capillary breakthrough pressure of the caprock (Chalbaud et al. 2010).

\section{3. In situ Trapping Mechanisms of Injected $\mathrm{CO}_{2}$}

435 Trapping mechanisms come under two major categories: physical and chemical 436 trapping mechanisms. Physical mechanism involves the trapping by structural and 
437 stratigraphic patterns of the aquifer sediment and caprock while chemical mechanisms 438 include dissolution in the brine, complex mineralisation with host rock, adsorption on 439 coal and $\mathrm{CO}_{2}$ hydrate formation (Espinoza et al. 2011). Some of these trapping 440 mechanisms are discussed below under the broad headings of structural, dissolution, 441 capillary and mineral trapping.

442

\subsection{Structural trapping}

444 Structural trapping arises from physical nature of the aquifer, e.g., anticlines or faults 445 intercepting the upward mobile plume of $\mathrm{CO}_{2}$. Together with stratigraphic as well as 446 hydrodynamic trappings, they constitute physical trapping mechanisms that control the 447 initial period of $\mathrm{CO}_{2}$ storage (White et al. 2001). Structural trapping occurs in the 448 presence of a structural enclosure together with a seal forming low permeability cap449 rock (Omambia and Y. Li 2010). The injected carbon dioxide rises to the upper layer of 450 the aquifer above the resident brine by the power of buoyancy and is immobilised under 451 the impermeable anticline structure. In a sequestration project at Sleipner (Norway) 452 structural traps are the key features focused upon prior to $\mathrm{CO}_{2}$ injection as they are key 453 to favourable geological site characterisation (Chadwick et al. 2008). From 1996, the $454 \mathrm{CO}_{2}$ plume had reached the top of the reservoir by 1999 at Sleipner (Shukla et al. 455 2010). Figure 5 depicts this mechanism in a reservoir as $\mathrm{CO}_{2}$ trapped under caprock.

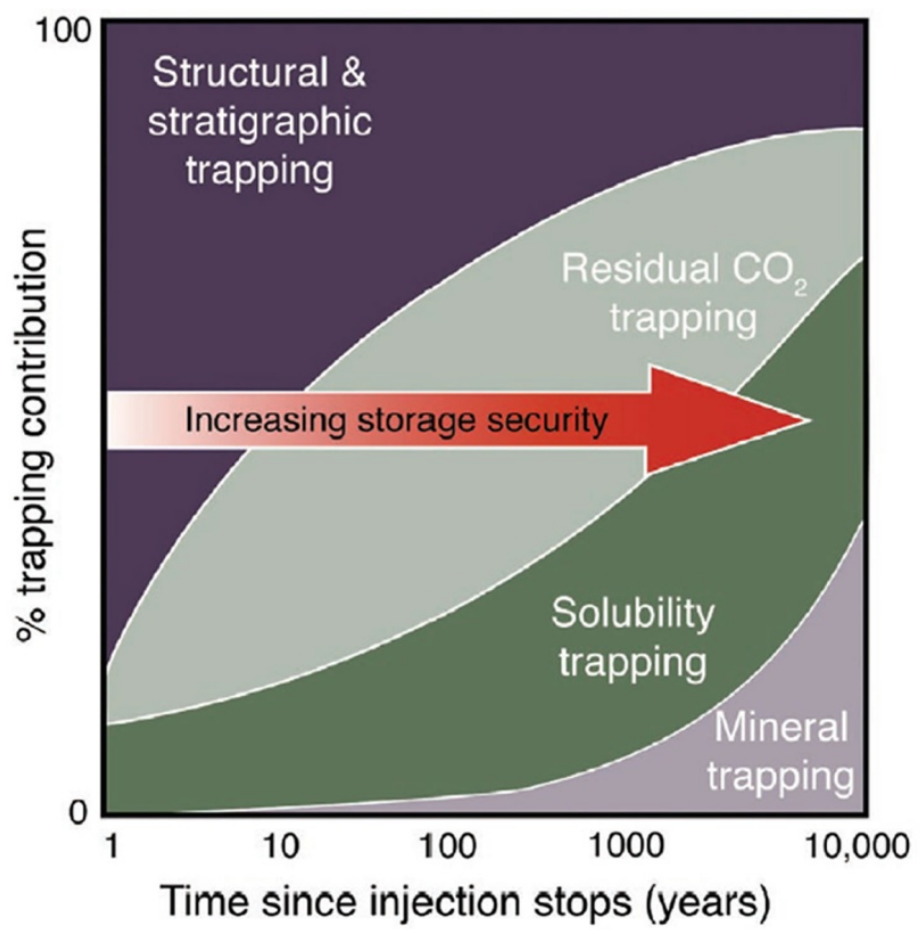

Figure 4: Mechanisms of $\mathrm{CO}_{2}$ Trapping with time (Benson and Cole 2008). 


\section{$460 \quad 3.2 \quad$ Residual trapping}

461 Residual trapping occurs as a result of a hysteresis effect in the permeability of the $462 \mathrm{scCO}_{2}$ phase especially when the saturation direction is reversed. It is a quick process 463 because of the tight and rigid sponge nature of the porous rock (Omambia and Li 2010). 464 As the $\mathrm{scCO}_{2}$ is injected into the deep aquifer formation, it displaces the resident fluid. 465 When the $\mathrm{scCO}_{2}$ continues to move, the previous brine takes its place trapping some of 466 the $\mathrm{scCO}_{2}$ adhered to the pore surface and stay behind trapped in the pore spaces as 467 residual droplets rendered immobile like water in a sponge (Ide et al. 2007). It is 468 depicted in Figure 5.

469

470 The trapping of a phase in this manner can be characterised by the relationship 471 between initial and residual saturation, known as the capillary trapping curve. This 472 phenomenon can be characterised by maximum trapped saturation and the form of the 473 capillary trapping curve as these depict the physics of this phenomenon and also give 474 an important indication of system wettability.

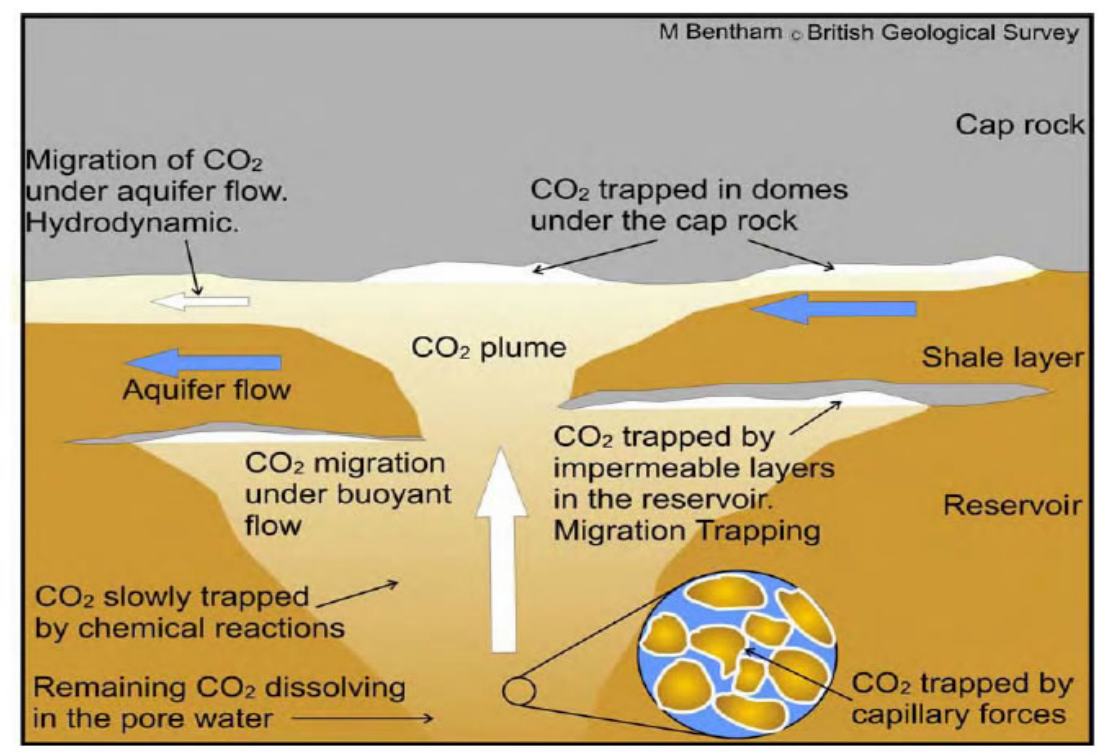

Figure 5: Various mechanisms of $\mathrm{CO}_{2}$ trapping in the reservoir (Bentham 2006)

\subsection{Solubility trapping}

479 It is envisaged that the long-term sequestration of $\mathrm{CO}_{2}$ in deep saline aquifers will occur via dissolution in the brine and/or chemical complexation with the formation (White et al. 2003). Solubility trapping occurs when $\mathrm{CO}_{2}$ in gaseous or supercritical state dissolves in

482 the aquifer brine at the prevalent conditions of temperature, salinity and pressure 483 (Omambia and Y. Li 2010). This results in the increase of the solution density and 
484 lowered $\mathrm{pH}$ as shown in Figure 6. As the $\mathrm{CO}_{2}$ dissolves in water, part of this mixes with 485 the water and form the carbonic acid which goes on to produce bicarbonate with 486 hydrogen ions. This reduces the $\mathrm{pH}$ of the system at reservoir conditions to 487 approximately 3 . The following steps represent the ionization process:

488

489

$$
\mathrm{CO}_{2}(\mathrm{~g}) \Leftrightarrow \mathrm{CO}_{2}(\mathrm{aq})
$$

$\mathrm{CO}_{2}(\mathrm{aq})+\mathrm{H}_{2} \mathrm{O}(\mathrm{l}) \Leftrightarrow \mathrm{H}^{+}+\mathrm{HCO}_{3}^{-}(\mathrm{aq})$

$\mathrm{HCO}_{3}^{-} \Leftrightarrow \mathrm{H}^{+}+\mathrm{CO}_{3}^{2-}(\mathrm{aq})$

490

491 Being heavier than other surrounding fluids as a result of the dissolved $\mathrm{CO}_{2}$, convective 492 currents are created causing the denser solution to settle at the bottom of the aquifer 493 trapping the $\mathrm{CO}_{2}$ more securely. The lighter brine with less dissolved $\mathrm{CO}_{2}$ then rises to 494 the top of the rock formation (Silin et al. 2008). The mass density of brine- $\mathrm{CO}_{2}$ solution, 495 $\rho_{\text {sol }}\left(\mathrm{kg} / \mathrm{m}^{3}\right)$, can be estimated from equation (11) (Espinoza et al. 2011):

496

497

$\rho_{\mathrm{sol}}=\rho_{\mathrm{w}}+\mathrm{m}_{\mathrm{CO}_{2}} \chi_{\mathrm{CO}_{2}}-\chi_{\mathrm{CO}_{2}} \rho_{\mathrm{w}} \mathrm{V}_{\varphi}$

498 (11)

499

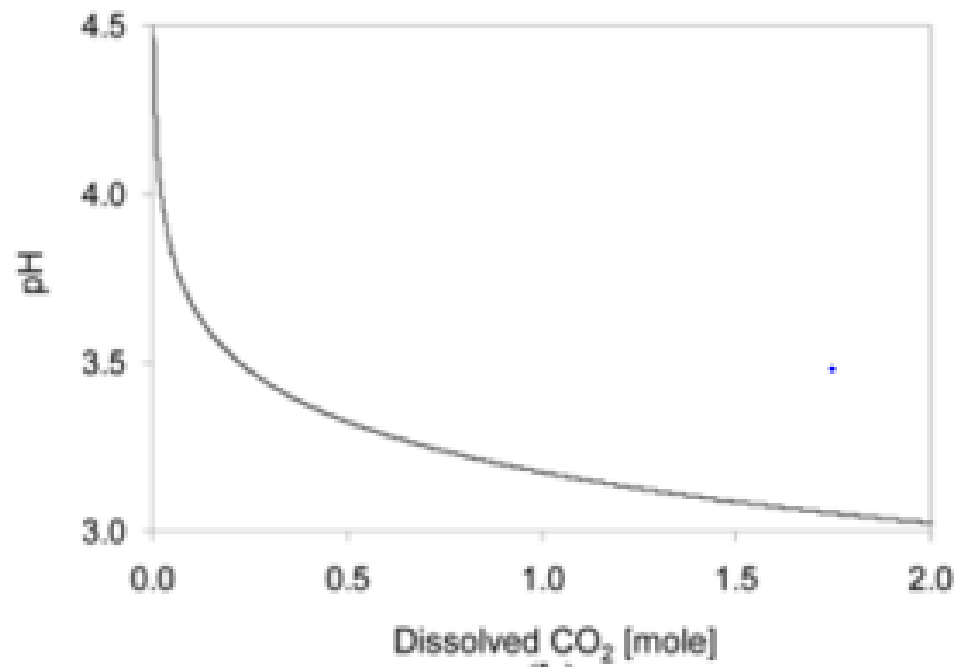

500 Figure 6: Solution $\mathrm{pH}$ as a function of solubility of $\mathrm{CO}_{2}$ in brine (Duan and Sun 2003).

501

$502 \rho_{\mathrm{w}}\left(\mathrm{kg} / \mathrm{m}^{3}\right)$ is the density of pure water, $\chi_{\mathrm{CO}_{2}}\left(\mathrm{~mol} / \mathrm{m}^{3}\right)$ is the $\mathrm{CO}_{2}$ concentration in water, $503 \mathrm{~m}_{\mathrm{CO}_{2}}(\mathrm{~kg} / \mathrm{mol})$ is the molecular weight of $\mathrm{CO}_{2}, \mathrm{~V}_{\varphi}\left(\mathrm{m}^{3} / \mathrm{mol}\right)$ is the apparent molar volume 504 of $\mathrm{CO}_{2}$ as a function of temperature, $\mathrm{T}(\mathrm{C})$ expressed by Garcia (2001) as $505 \mathrm{~V}_{\varphi}=37.51 \cdot 10^{-6}-9.585 \cdot 10^{-8} \mathrm{~T}+8.740 \cdot 10^{-10} \mathrm{~T}^{2}-5.044 \cdot 10^{-13} \mathrm{~T}^{3}$. Densification of the 
506 brine- $\mathrm{CO}_{2}$ solution promotes the convective mixing in the aquifer, which improves the 507 effectiveness of this trapping mechanism. This continues until the system reaches 508 equilibrium condition.

509

510 Solubility is affected by the temperature and pressure of the system, pore size 511 distribution. So, the choice of basins with higher density of large pores will aid this 512 mechanism (Emmanuel et al. 2010). The dissolution increases with pressure and 513 decreases with temperature as shown in the chart presented by Dodds et al. (1956) 514 with different patterns of dissolution below and above critical conditions. Also, salt 515 concentration of the brine has been shown to affect the solubility of $\mathrm{CO}_{2}$. There appear 516 to be an indirect linear relationship between $\mathrm{CO}_{2}$ solubility and salt concentration as 517 shown in Figure 7. This implies that aquifer with lower brine concentration favor $s$ this 518 dissolution mechanism.

519

520 A dimensionless number, namely, Rayleigh number ( $\mathrm{Ra})$ is important in the dissolution521 convection processes involved in the solubility trapping. $\mathrm{Ra}$ is particularly associated 522 with buoyancy-driven flow. It is dependent on the fluid property and the characteristic 523 length of the system expressed as (Farajzadeh 2009): $R a=\frac{\beta_{c} g \Delta c R^{3}}{v D} \cdot \beta_{c}$ is the

524 volumetric expansion coefficient $\left(\mathrm{m}^{3} / \mathrm{mol}\right), \mathrm{g}$ is the acceleration due to gravity $\left(\mathrm{m} / \mathrm{s}^{2}\right), \mathrm{c}$ 525 is the gas concentration $\left(\mathrm{mol} / \mathrm{m}^{3}\right), \mathrm{R}$ is the characteristic length of the system $(\mathrm{m}), v$ is 526 the kinematic viscosity $\left(\mathrm{m}^{2} / \mathrm{s}\right)$ and $D$ is the diffusion coefficient $\left(\mathrm{m}^{2} / \mathrm{s}\right)$. As Ra increases 527 mass transfer of $\mathrm{CO}_{2}$ into the brine-saturated porous medium increases and the 528 concentration front moves faster (Farajzadeh 2009). Low Ra results into the steady529 state concentration while its high value leads to the system instability (Ouakad 2013).

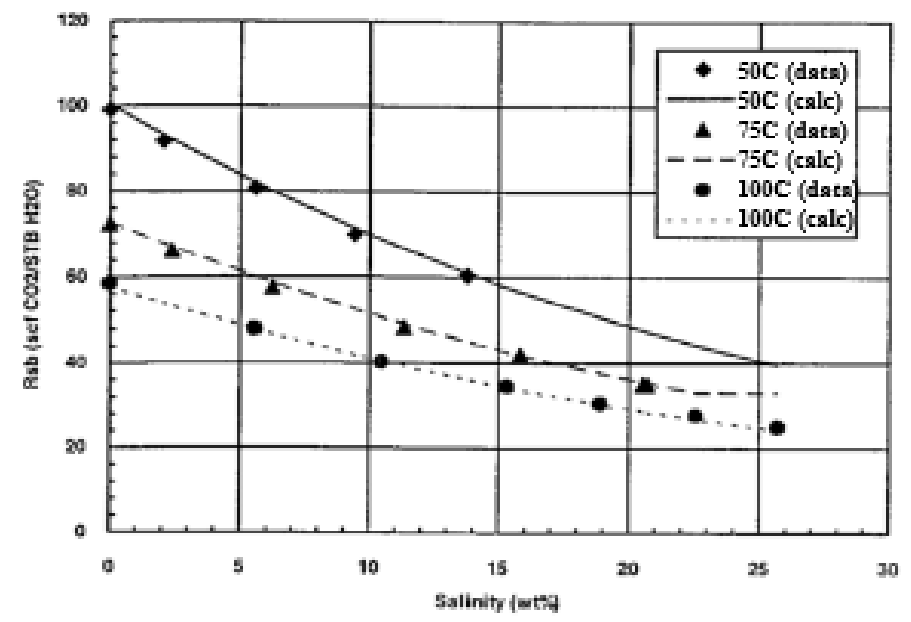


531 Figure 7: $\mathrm{CO}_{2}$ solubility as a function of salinity (Chang et al. 1998)

532

\section{$533 \quad 3.4 \quad$ Mineral trapping}

534 When carbon dioxide is dissolved in brine, it decreases the $\mathrm{pH}$ of the solution leading to acidification as expressed in equation (10). This acidified solution in contact with host rock results in mineral dissolution, precipitation and reactions, which are the processes that induce mineral trapping. With time, the reactions of the acid with dissolved ions and rock minerals in the aquifer lead to chemical complexes such as magnesite, dolomite, calcite, drawsonite and siderite. These occur as products of dissolution and complexing, resulting in chemical precipitation of solid carbonate minerals (secondary carbonates).

541 It is regarded as a permanent sequestration process. However, it is a slow process with

542 significant contribution occurring only in the geological time scale.

544 Reaction between $\mathrm{CO}_{2}$ and alkali aluminosilicate minerals will generate a soluble alkali 545 bicarbonates as well as carbonates promoting the mechanism of solubility trapping. In 546 this line of series, parallel and complex reactions and processes, $\mathrm{pH}$ of the system 547 changes dramatically as the dissolution of carbonates ions raises it up to 5 while 548 aluminosilicates can take the $\mathrm{pH}$ up to 8 (Espinoza et al. 2011).

550 Beni et al. (2012) evaluated the potential of mineral trapping on $\mathrm{CO}_{2}$ sequestration in 551 the sandstone formation near Minden in Germany. They found that after about 200 552 years, this mechanism contributes significantly in the storage and the prospect 553 increases even more with time.

554

555 Typical reaction with silicate mineral is represented below (Drever and Stillings 1997): 556

$$
\mathrm{SiO}_{2}(\mathrm{~s})+2 \mathrm{H}_{2} \mathrm{O} \Leftrightarrow \mathrm{H}_{4} \mathrm{SiO}_{4}
$$

$$
\Leftrightarrow \mathrm{H}^{+}+\mathrm{H}_{3} \mathrm{SiO}_{4}^{-}
$$

$\Leftrightarrow \mathrm{H}^{+}+\mathrm{H}_{2} \mathrm{SiO}_{4}^{-}$

\section{8 (12)}

559 Equation (12) has a reaction rate of $1.26 \times 10^{-14} \mathrm{~mol} \cdot \mathrm{m}^{-2} \cdot \mathrm{s}^{-1}$ (White et al. 2004) and the 560 reaction is not affected by dissolution of $\mathrm{CO}_{2}$. But the reaction with aluminosilicates

561 (including feldspars, micas, clays) turns the system alkaline with $\mathrm{pH}$ up to 8 (Li et al. 562 2006) while faster carbonate reactions raise the pH up to 5 (Algive et al. 2009). 


\section{Modelling and simulations of $\mathrm{scCO}_{2}$-brine-rock system}

565 Modelling and simulations of geological sequestration processes are highly required to assess the feasibility of $\mathrm{CO}_{2}$ sequestration into particular aquifer or reservoir. Modelling

567 the sequestration entails considerations for the technicalities of the storage systems and the economics. This ranges from capture, transport and storage together with the associated costs brought together in a discounted cash flow calculations (Chadwick et al. 2008). However, the interest of this section is to discuss the basics of modelling and

571 simulations involved in geological sequestration.

572 Generally, the geological sequestration systems can be described using multiphase 573 and multi-component processes with consideration for non-isothermal conditions 574 occurring near the injection region owing to $\mathrm{CO}_{2}$ expansion with Joule-Thompson 575 effects (Class et al. 2009). Basic multiphase equations are built upon mass and 576 momentum conservations as well as various constitutive equations. For the 577 simultaneous flow of $\mathrm{CO}_{2}$ and water, the governing equations can be expressed as:

582 ' $\mathrm{i}$ ' stands for the phases; $\mathrm{CO}_{2}(\mathrm{~g})$ or brine/water (w). $\mathrm{S}$ is the phase saturation and $\mathrm{q}$ the 583 velocity and $\phi$, the porosity. . The velocity $q$ is given by the extended version of Darcy's 584 law; $q_{i}=-\frac{K_{r i} K}{\mu_{i}}\left[\nabla P_{i}+\rho_{i} g \nabla z\right]$. For radial injection in the aquifer (Saripalli et al. 2001); $585 \quad \mathrm{q}_{\mathrm{r}, \mathrm{i}}=\frac{\mathrm{Q}_{\mathrm{i}} \mathrm{f}_{\mathrm{i}}\left(\mathrm{S}_{\mathrm{i}}\right)}{2 \pi \mathrm{rh}} \cdot \mathrm{K}_{\mathrm{ri}}$ represents the relative permeability for phase $\mathrm{i}$ and $\mathrm{K}$ is the medium 586 intrinsic permeability. $P$ is the phase pressure, $\rho$ the density and $g$ is the acceleration 587 due to gravity, $\nabla z$ is the gradient of upward unit vector. $Q$ is the injection rate and $f$ is 588 the phase fractional flow. For the injected phase, substituting for radial velocity in 589 equation (13) results into two-phase displacement theory based on the Buckley590 Leverette theory (Saripalli et al. 2001):

591

592

$$
\frac{\mathrm{Q}_{g} \mathrm{f}_{\mathrm{g}}}{2 \pi \mathrm{rh} \phi} \frac{\partial \mathrm{S}_{\mathrm{g}}}{\partial \mathrm{r}}+\frac{\partial \mathrm{S}_{\mathrm{g}}}{\partial \mathrm{t}}=0
$$


595 In addition to the above, a detailed description of the constitutive equations for the 596 sequestration system requires several mathematical expressions which include the $\mathrm{CO}_{2}$ 597 saturation in the expanding radial plume and its derivative, equation of state for the 598 phase partitioning behaviour of $\mathrm{CO}_{2}-\mathrm{H}_{2} \mathrm{O}$ mixture, models for dissolution of $\mathrm{CO}_{2}$ in brine 599 and vice versa with their derivatives along the horizontal and vertical regions and 600 pressure distribution in the region of the plume. While the radial flow of the injected 601 phase is inserted as velocity in the equation (14) (Saripalli et al. 2001), the buoyant flow 602 of the process needs a separate velocity expression as a function of radius. 603 Furthermore, incorporating expressions for leaks is desired for robust modelling and 604 analysis of injection and sequestration processes.

605

606 For $\mathrm{CO}_{2}$ leaks scenarios, two significant processes are of concern: vertical migration as 607 a free phase through fractures and buoyancy driven flow through permeable zones of a 608 water-saturated caprock were identified (Huo and Gong 2010; Saripalli et al. 2001). 609 Young-Laplace relation for capillary pressure provides a handy expression for 610 determining the entry capillary pressure from the values of two-phase interfacial tension 611 and pore size obtained for the caprock (Singh et al. 2010). Thickness of the $\mathrm{CO}_{2}$ bubble 612 layer near the caprock will provide the needed parameter for the exerted pressure on 613 the confinement and expression for free phase flow of $\mathrm{CO}_{2}$ through the aperture is 614 required for the complete description of the leak scenario. In very robust case, 615 incorporating chemical reactions from dissolution, mineral precipitations, various 616 trapping mechanisms are highly desired. The above scheme can be simplified for easy 617 solution depending on the level of analysis desired but the more processes that are incorporated into the model the better the simulation and the more robust and better its application. This calls for the assessment of the currently available simulators. Though,

620 it is recognised that the solution methods become complicated with complex multi621 process models.

623 Popular approaches to the solution of mathematical modelling are analytical, semi 624 analytical and numerical techniques. For example, Woods and Comer. (1962) obtained analytical solution to equation (14) for radial injection of gases into initially watersaturated reservoir. Similarly, Nordbotten et al. (2005) provide analytical solution to the

627 space-time evolution of $\mathrm{CO}_{2}$ plume. However, for very complex problems, non-linearity 628 in constitutive relations often defies analytical solution. As such, numerical solution is 629 often applied. Numerical solution allows simulations that incorporate diverse injection 
630 wells with varying injection rates, heterogeneous geologic formations, and simultaneous 631 chemical reactions as well as mass transfer processes. If sufficient data are available, 632 achievable $\mathrm{CO}_{2}$ saturation, local or regional pressure constraints, dissolution as well as 633 residual saturation can be assessed with numerical simulation as they are dependent 634 mainly on the reservoir and fluid properties as well as injection strategies (Chadwick et 635 al. 2008).

637 Software designed for hydrocarbon systems in the oil industries are easily adaptable to $638 \mathrm{CO}_{2}$ storage as evident by code inter-comparison study (Pruess et al. 2003). However, currently many numerical simulators have emerged in the field of sequestration processes with function-specific as well as general applications. They include NUFTSYNEF (Morris et al. 2011a; Morris et al. 2011b), STOMP (White 2002), FEMH (Bower and Zyvoloski 1997), ECLIPSE-VISAGE (Ouellet et al. 2011), OpenGeoSys (Wang and Kolditz 2007), TOUGH2 (Pruess et al. 1999), TOUGHREACT (Xu et al. 2006), TOUGHFLAC (Rutqvist 2011; Rutqvist et al. 2002), CODE-BRIGHT (Olivella et al. 1994; Vilarrasa et al. 2010), DYNAFLOW (Preisig and Prévost 2011), STARS (Bissell et al. 2011). Also, COORES, DuMux, GPRS, MUFTE, MoReS, ROCKFLOW and ELSA are some of the models with capability for simulating different carbon sequestration scenarios and are involved in the benchmark study for the inter comparison of mathematical and numerical models in the context of geological carbon sequestration (Class et al. 2009). In some (e.g., TOUGHREACT) fluids and heat flows are coupled with reactive geochemistry to enhance applications in geological carbon sequestration.

653 The simulation code, 'subsurface transport over multiple phases (STOMP)' developed 654 using advance computational tools by Pacific Northwest National Laboratory (PNNL, Washington) has the ability for simulating fully coupled mass and heat transport with kinetic and/or equilibrium controlled chemical reactions, temporal and spatial responses 657 to injection, injectivity, hydrogeological and fluid properties change (White and McGrail 2005). Class et al. (2009) emphasised the investigation of influence of gridding, model concepts and mechanisms to ensure quality control and assessment of numerical simulators. However, further developments are required in the ability of the simulators to quantify and relate leak factors on a site-specific basis. This should establish the threshold values that may compromise the reservoir integrity. For example, one needs to determine what quantity of $\mathrm{CO}_{2}$, in conjunction with gas-brine-rock interactions and 664 time will result in leakage. Ability to easily predict this scenario will afford the 
665 researchers the opportunity to establish site-specific limit of injection. For example, the 666 work of Schwartz (2014) using TOUGHREACT presented a leakage factor: 667 transmissibility. This was established for a potential leak zone as a product of width and 668 permeability with a threshold value of $1.7 \times 10^{-3} \mathrm{~m}^{3}$. This is established based on the 669 media property. However, such threshold established on gas-brine-media and time 670 factors together with associated geophysical and geochemical processes will serve a 671 caution on the limit of sequestration for site-specific assessments.

673 5. $\mathbf{P}^{\mathrm{C}}-\mathrm{S}-\mathrm{K}_{\mathrm{r}}$ relationships and phase characteristics in $\mathrm{ScCO}_{2}$-brine system

674 Some properties of $\mathrm{CO}_{2}-$ water system had been discussed above and are shown to be 675 temperature and pressure dependent. Among them, the interfacial tension of $\mathrm{CO}_{2}$-water 676 had been shown to decrease with increasing pressure and attains a plateau in the 677 supercritical state (Espinoza and Santamarina 2010; Kvamme et al. 2007). In contrast, 678 contact angle of the system also changes with pressure relative to the wettability of the 679 medium. It increases with pressure on oil-wet surfaces and decreases slightly on water680 wet surfaces (Chiquet et al. 2007; Espinoza et al. 2011). The implication of this 681 behaviour on two-phase flow characteristics can be discerned based on Young-Laplace 682 relation: $P^{c}=\frac{2 \gamma^{w n} \cos \theta}{r}$ where $P^{c}$ decreases with decrease in interfacial tension, $\gamma^{\text {wn }}$, 683 and increase in contact angle. Researchers of multiphase flow have reported patterns 684 of $P^{c}-S-K_{r}$ relationship for multiphase flow and expatiated on number of factors 685 affecting these relationships. Most of the works are published for oil-water system but of 686 recent, we can find some studies relating to carbon sequestration. Changes in the 687 interfacial tension as well as the contact angle will have impact on capillary pressure, 688 residual saturation, evolution of flooding, capillary effects and relative permeabilities 689 (Espinoza et al. 2011). Below, we examine the reports presented and the approaches 690 adopted.
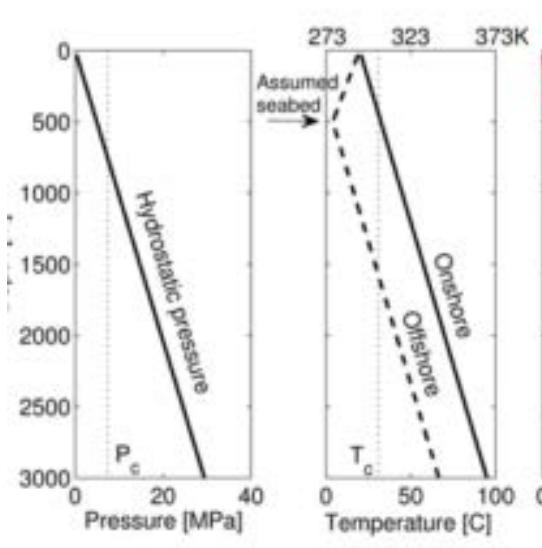
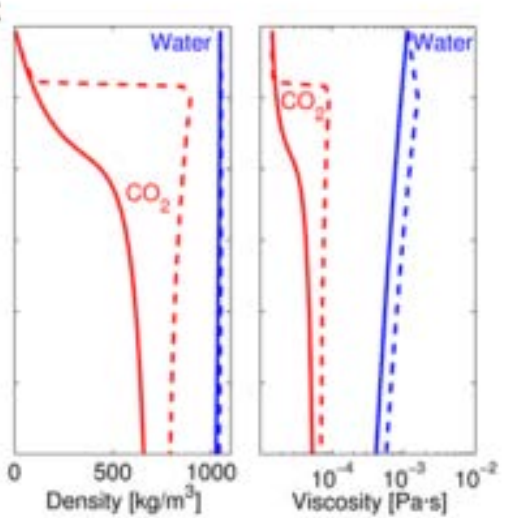

Page 24 of 56 
692 Figure 8: Density and viscosity of water and $\mathrm{CO}_{2}$ with depth (Espinoza et al. 2011)

693

\subsection{Effects of viscosity and density ratios of $\mathrm{CO}_{2}$ on $\mathbf{P}^{\mathrm{c}}-\mathrm{S}-\mathrm{K}_{\mathrm{r}}$ relationships}

695 The density and viscosity of the $\mathrm{CO}_{2}$ have been shown to vary under different 696 conditions of pressure and temperature. In Figure 8, the density of $\mathrm{CO}_{2}$ can be seen 697 following nonlinear rise from the surface to the injection bed about $1 \mathrm{~km}$ below ground 698 and then follow a fairly straight line into a deeper injection field about $3 \mathrm{~km}$ down for the 699 onshore sequestration. For the offshore operation this pattern changes as the density 700 rises rapidly around the sea bed and then remains almost constant henceforth and 701 larger at the same depth compared to onshore. In another part of the figure, the 702 viscosity of $\mathrm{CO}_{2}$ in offshore and onshore follows similar though with slight variation in

703

704

705

706

707

708

709

710

711 is mathematically expressed for viscosity as: $\mu_{\mathrm{r}}=\frac{\mu_{\mathrm{CO}_{2}}}{\mu_{\mathrm{w}}}$ and density as: $\rho_{\mathrm{r}}=\frac{\rho_{\mathrm{CO}_{2}}}{\rho_{\mathrm{w}}}$,

712 respectively. While discussing the rate dependency of the $\mathrm{P}^{c}-\mathrm{S}-\mathrm{K}_{\mathrm{r}}$ relationships for oil-water system, Joekar-Niasar and Hassanizadeh (2011) stated that the invading front in a two-phase system becomes unstable if the viscosity ratio is less than one under drainage or if greater than unity under imbibition while the front becomes stable if the ratio is higher than one in drainage and lower than one in imbibition. This implies that

717 the displacement of brine by $\mathrm{scCO}_{2}$ may face instability and the lower the viscosity ratio at shallower depth, the higher the instability at the displacement front.

720 Das et al. (2007) pointed out that density ratio effect on $\mathrm{P}^{c}-\mathrm{S}-\mathrm{K}_{\mathrm{r}}$ relationships is 721 dependent on the flow direction. The saturation-rate dependency of the relationships 722 also known as dynamic effect increases as density ratio increases if the flow is in downward direction while the trend is still on the increase for decreasing density ratio if

724 the flow is in the upward direction (Das et al. 2006). Implication of the above discussion 
725 in the characterisation of $\mathrm{P}^{\mathrm{c}}-\mathrm{S}-\mathrm{K}_{\mathrm{r}}$ relationships for the $\mathrm{ScCO}_{2}$-brine system in 726 different geological media will require applicable mathematical functions, which in no 727 doubt will be complex. Otherwise, the relationship will be determined for individual site.

\subsection{Instability in the displacement of fluid/fluid interface in $\mathrm{scCO}_{2}$-brine-porous} media system

In a two-phase system in porous media, instability at the displacement front can occur because of the higher mobility phase displacing a lower mobility phase as in the case of $\mathrm{scCO}_{2}$-brine system leading to fingering of the displacing phase (Berg and Ott 2012). This can be observed in both miscible and immiscible displacement conditions (Meurs 1957; Taylor 1958). Analytical model by Van Wunnik and Wit (1989) had earlier shown the source of this condition to be as a result of viscous pressure gradient leading to a steeper pressure gradient of the lower-mobility phase letting the finger grow. Among the factors controlling this condition, mobility is defined as the ratio of the relative permeability $\left(K_{r}\right)$ of the phase to its viscosity $(\mu)$ and mobility ratio $(m)$ as the ratio of the mobility of the displacing phase to that of the displaced. For $\mathrm{CO}_{2}$ displacing brine, $\mathrm{m}$ is expressed in equation (15):

$$
\mathrm{m}=\frac{\mathrm{K}_{\mathrm{rn}} / \mu_{\mathrm{n}}}{\mathrm{K}_{\mathrm{rw}} / \mu_{\mathrm{w}}}
$$

$\mathrm{K}_{\mathrm{rn}}$ and $\mu_{\mathrm{n}}$ are the relative permeability and viscosity of $\mathrm{CO}_{2}$ ), respectively while the $\mathrm{K}_{\mathrm{rw}}$ and $\mu_{\mathrm{w}}$ are the respective relative permeability and viscosity of water. It determines the stability and the efficiency of the displacement (Berg and Ott 2012) which becomes unstable at high $\mathrm{m}$ resulting in viscous fingering (Salimi et al. 2012). This is enhanced by the much lower viscosity of the $\mathrm{CO}_{2}$.

752 Furthermore, capillarity was identified as another factor of importance affecting 753 instability growth rate (Yortsos and Hickernell 1989; Babchin et al. 2008) causing 754 'capillary dispersion' (Riaz and Tchelepi 2004) by which a sharp front becomes 755 transformed into a diffused zone with elongated tail (Berg and Ott 2012). This dispersion effect acts to suppress finger (Homsy 1987). In addition, the scale of consideration determines the influence of this capillarity as the dispersion occurs at the 
758

759

760

761

762

763

764

765

766

767

768

769

770

771

772

773

774

775

776

777

778

779

780

781

782

783

784

785

786

787

788

789

790

791

same length scale as the shock front. Capillary number, $\mathrm{Ca}$, is used to quantify the influence of this force and it is defined as the ratio of the viscous to capillary forces expressed as: $\mathrm{Ca}=\mu \mathrm{V} / \gamma, \mu$ is the viscosity of the displacing fluid, $\mathrm{V}$ the characteristic velocity and $\gamma$ is the interfacial tension between the two phases. Change in $\mathrm{Ca}$ has been shown to affect the stability of the two-phase displacement patterns at different values of $\mathrm{m}$. Numerical simulations results by Lenormand et al. (1988) showed that at high $\mathrm{m}$ and low $\mathrm{Ca}(-8<\log \mathrm{Ca}<-6)$, capillary fingering dominates the displacement which becomes stable at high $\mathrm{Ca}$ (Figure 9a). At low m (Figure 9b), there exists a crossover region as the $\mathrm{Ca}$ increases. At this region the displacement mechanisms switches from the capillary to viscous fingering. Noticeable from the figure, at high $\mathrm{m}$, is the improved saturation of the displacing phase as the displacement transitioned to stable displacement at appropriate $\mathrm{Ca}$. Also, the figure showed the possibility of inefficient storage that may result from operating under viscous fingering at low $\mathrm{m}$. Wang et al. (2013) demonstrated the influence of the $\mathrm{Ca}$ and the significance crossover on the displacement of water by $\mathrm{scCO}_{2}$. They found increase in $\mathrm{scCO}_{2}$ saturation as the $\log \mathrm{Ca}$ increases from -7.61 to -6.61 where capillary fingering dominates. At higher injection rates, viscous fingering dominates, and the $\mathrm{scCO}_{2}$ saturation remains nearly constant.

Furthermore, the Ca equation, shown above, indicates the importance of the interfacial tension in the two-phase flow system. This also tells us some information about the stability of the system. For example, in the numerical simulation by Berg and Ott (2012), low interfacial tension in the range of $0-0.05 \mathrm{mN} / \mathrm{m}$ generally leads to unstable displacement while marginal stability is recorded at $0.1 \mathrm{mN} / \mathrm{m}$. For interfacial energy that is greater than $1 \mathrm{mN} / \mathrm{m}$, it becomes stable at an experimental scale.

Various factors have been reported to affect the $\gamma$ between $\mathrm{CO}_{2} /$ water or $\mathrm{CO}_{2} /$ brine system. These include the temperature, pressure, salt concentrations and type of ions in the system. Under similar conditions, $\gamma$ for $\mathrm{CO}_{2} /$ water and $\mathrm{CO}_{2} /$ brine show similar evolution with respect to temperature and temperature (Chun and Wilkinson 1995; Chalbaud et al. 2010). It decreases with pressure at constant temperature and this is more significant at lower pressure near the critical region (Nielsen et al. 2012; Shojai Kaveh et al. 2011) especially at low temperature (Chalbaud et al. 2010). At higher pressure, plateau is reached at the value of $\gamma$ for the system that slight increases with 
salt concentration at constant temperature (Chalbaud et al. 2010). This behaviour has

793 been attributed to the solubility effects of $\mathrm{CO}_{2}$ which increases with pressure at low 794 pressure and remains nearly unchanged at higher pressure when the difference in 795 densities between $\mathrm{CO}_{2}$ and brine remains constant. Considering the dissolution effect 796 on the density difference $(\Delta \rho)$ become more important at high pressure since $\gamma$ calculation is a linear function of $\Delta \rho$ (Chalbaud et al. 2010; Chiquet et al. 2007). For a given height of stored $\mathrm{CO}_{2}$, underestimating the $\gamma$ between $\mathrm{CO}_{2}$ /water will lead to 799 overestimating the displacement efficiency making it seem like there is more space for 800 storage than in reality (Chalbaud et al. 2010). The valence of the cations present in the 801 gas-brine-rock system has been shown to be important in the value of the $\gamma$. For $\mathrm{CO}_{2}$ 802 water system, $\gamma$ is more than twice higher for the divalent cation (e.g., $\mathrm{Ca}^{+2}$ ) than the 803 monovalent type e.g., $\mathrm{Na}^{+}$(Aggelopoulos et al. 2010).

804

805

In addition, the viscosity ratio and the non-wetting phase saturation have relation to the 806 $\mathrm{Ca}$ and the stability of the two-phase system. Zhang et al. (2011) observe higher 807 incident of viscous fingers in the two-phase flow at high $\mathrm{Ca}$. For very low viscosity ratio, 808 unstable displacement dominates with the viscous fingers for all $\mathrm{Ca}$. For moderately low 809 viscosity ratio, there exists a value in $\mathrm{Ca}$ at which there is a crossover from unstable to stable displacement. This condition corresponds to $\log \mu_{r}>0$ (Zhang et al. 2011). Based

811 on Figure 8 , at moderate depths of the aquifers (between 500 to $1000 \mathrm{~m}$ ), stable 812 displacement is enhanced at offshore sites where $\mathrm{CO}_{2}$ viscosity is higher.
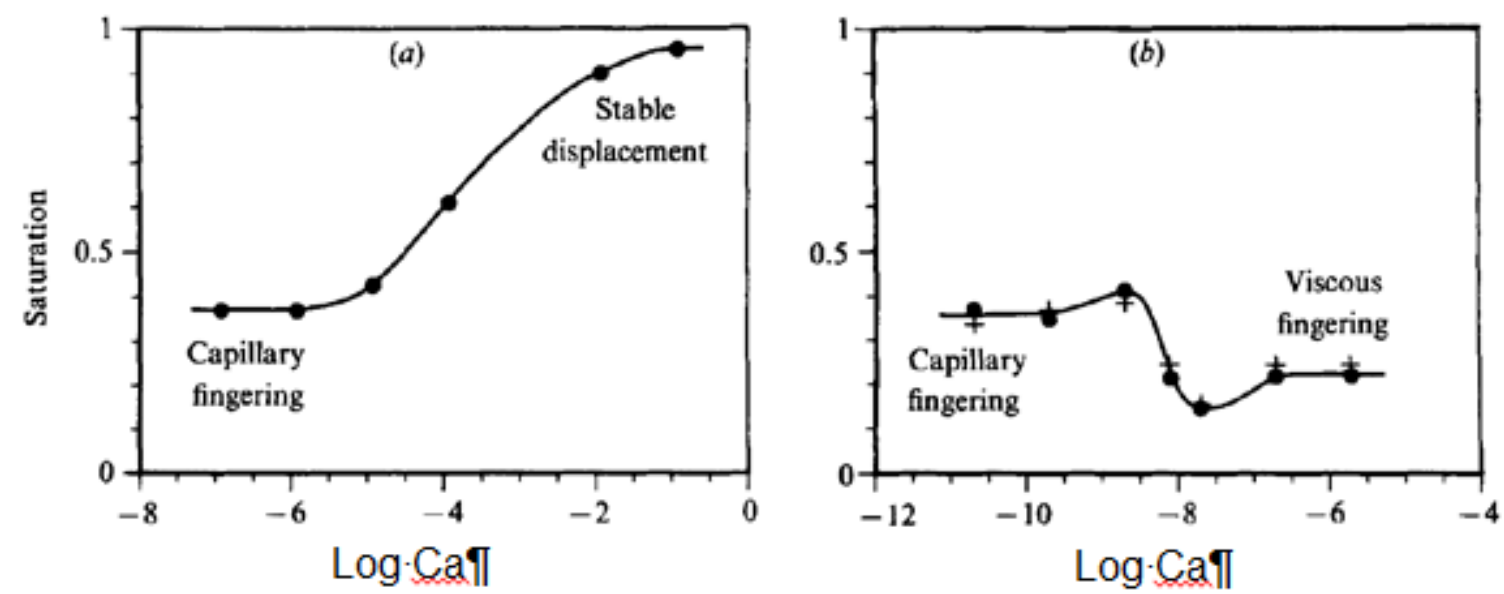

815 Figure 9: Capillary number and the displacement in the two-phase system (a) high 816 viscosity ratio $(\log m=1.9$ ), (b) low viscosity ratio ( $\log m=-4.7)$. Vertical axis 817 represents the saturation of the displacing phase (Lenormand et al. 1988). 
819 Authors like Plug and Bruining (2007) and Plug et al. (2006) acknowledge that the 820 supercritical $\mathrm{CO}_{2}$ state is prone to phase transition together with property fluctuation.

821 These behaviours may not be unexpected to affect the stability and the $P^{c}-S-K_{r}$ 822 relationships for the system. Plug and Bruining (2007) observed irregular $\mathrm{P}^{\mathrm{C}}-\mathrm{S}$ 823 relationships for supercritical $\mathrm{CO}_{2}$ (at $40^{\circ} \mathrm{C}$ and 85 bar) under drainage while usual $\mathrm{P}^{\mathrm{C}}-\mathrm{S}$ 824 curve pattern was obtained for liquid $\mathrm{CO}_{2}\left(27^{\circ} \mathrm{C}\right.$ and 85 bar $)$. This was attributed to $825 \mathrm{CO}_{2}$-wet behaviour or occasional imbibition of water during the process. This behaviour 826 can also be viewed as part of the manifestation of the above-described instability in the 827 displacement. $\mathrm{ScCO}_{2}$ phase undergoes irregular transition in properties and 828 characteristics at slight change of temperature, pressure and velocity which are difficult 829 to maintain constant in the system. The fact that this is absent in liquid case points to 830 the fact that reduced interfacial tension in $\mathrm{ScCO}_{2}$ (Nielsen et al. 2012; Espinoza and 831 Santamarina 2010) may be responsible judging from the report of Berg and Ott (2012). 832 Both authors (Nielsen et al. 2012; Espinoza and Santamarina 2010) reported that the 833 interfacial tension of $\mathrm{CO}_{2}$-water system reduces with pressures but levels off above the $834 \mathrm{CO}_{2}$ critical condition ( $\left.7 \mathrm{MPa}\right)$ at fixed temperature (Nielsen et al. 2012). However, the 835 work of Kaveh et al. (2013) show that the decrease continues up to 100 bar. 836 Furthermore, the sharp deviation in contact angle from the subcritical to supercritical 837 regions of $\mathrm{CO}_{2}$ (Saraji et al. 2013) show that phase transition holds important 838 information about the phenomena in the $\mathrm{scCO}_{2}$-brine system. Considering these cases, 839 phase transition in the geological media in conjunction with numerous subsurface 840 processes associated with $\mathrm{ScCO}_{2}$-brine and porous media systems may be complex 841 and point finger at the system stability and reliability.. This calls for more understanding 842 of the fluid-fluid-media system and characteristics, e.g., $\mathrm{P}^{\mathrm{C}}-\mathrm{S}-\mathrm{K}_{\mathrm{r}}$ relationships under the 843 varying conditions. $\mathrm{K}_{\mathrm{r}}-\mathrm{S}$ functions is essential for accurate analyses of the $\mathrm{CO}_{2}$-water 844 displacement process (Berg and Ott 2012).

845

\section{$846 \quad 5.3 \quad$ Influence of pressure, dissolution and wettability}

847 The comparisons made between $\mathrm{N}_{2}$ and $\mathrm{CO}_{2}$ experiments by the Plug and Bruining 848 (2007) showed that $\mathrm{CO}_{2}$ dissolution in water results in lower residual gas saturation. 849 This is similar to the findings of Pistone et al. (2011). Also, the capillary pressure of $850 \mathrm{scCO}_{2}$ was found to be lower if compared to gas and liquid $\mathrm{CO}_{2}$ at every corresponding 851 saturation. Several authors (Tokunaga et al. 2013; Plug and Bruining 2007) are 
unanimous in their observations that the $\mathrm{P}^{\mathrm{c}}-\mathrm{S}$ relationships decrease as pressure 853 increases owing to decreasing interfacial tension (Chun and Wilkinson 1995; Espinoza 854 et al. 2011) while for secondary imbibition the negative $P^{c}$ at around high water saturation was attributed to alteration in wetting behaviour (Plug and Bruining 2007). Though the effects of dissolution were more pronounced for the $\mathrm{CO}_{2}$ injection compared to $\mathrm{N}_{2}$, the capillary pressure was said not to be affected by the dissolution since the $\mathrm{P}^{\mathrm{C}}$ curves in both cases appear in the same range. But, it is well known that the dissolution effects act to reduce the surface tension of a two-phase system as earlier pointed out by Bennion and Bachu (2008) for $\mathrm{CO}_{2}$-brine and $\mathrm{H}_{2} \mathrm{~S}$-brine systems. Therefore, it is difficult to rule out the effect of dissolution on the observed differences in $\mathrm{P}^{\mathrm{C}}$-S at higher pressures. For $\mathrm{ScCO}_{2}$, small perturbations in the system dynamics cause sudden events resulting in the spontaneous imbibition of water into the system during drainage (Plug and Bruining 2007). This results in a decreasing capillary pressure and an irregular drainage curve. Also, wettability effect showed that the sand remains water-wet going by the positive drainage capillary pressure measured for all temperature and pressure conditions considered. Plug et al. (2006) showed that coal bed was water-wet in primary drainage but increasing pressure changes this to $\mathrm{CO}_{2^{-}}$ wet condition in medium rank coal. They found that the effects of adsorption were not very pronounced with the significant $\mathrm{CO}_{2}$-wet condition re-occurring for the imbibition processes conducted. Their reports concluded that imbibition experiments provide good qualitative information regarding the wettability of coal.

\section{$874 \quad 5.4 \quad P^{c}-S-K_{r}$ relationships in consolidated porous rocks}

875 The work of Pini et al. (2012) reported $P^{c}-S$ for consolidated media, namely, the 876 Berea and Arqov sandstone samples. Discussing the relation in reference to 877 temperature, the $\mathrm{P}^{\mathrm{c}}-\mathrm{S}$ curves for the Berea sandstone showed that capillary pressure 878 decreases as temperature reduces and this behaviour was attributed to increase in $\mathrm{CO}_{2}$ 879 dissolution as the temperature decreases reducing the interfacial tension. By 880 implication, the supercritical $\mathrm{CO}_{2}$ will have a higher $\mathrm{P}^{\mathrm{c}}$ than liquid $\mathrm{CO}_{2}$. But this will 881 contradict the conclusion of other authors that the liquid $\mathrm{CO}_{2}$ has higher $\mathrm{P}^{\mathrm{C}}$ than $\mathrm{scCO}_{2}$ 882 (Plug and Bruining 2007). Also, the $\mathrm{P}^{\mathrm{C}}-\mathrm{S}$ profile in Berea sandstone, described as 883 well sorted and homogenous sample, was consistently low for wide range of saturation 884 with sharp rise in $\mathrm{P}^{\mathrm{c}}-\mathrm{S}$ values close to irreducible saturation. In comparison, the 885 Arqov sample described as heterogeneous in nature displays a sharper rise and 
broader distribution in $\mathrm{P}^{\mathrm{c}}-\mathrm{S}$ while the profile remains considerably higher than in

887 Berea sandstone for most of the saturation values. This brings to mind the influence of 888 heterogeneities in $\mathrm{P}^{\mathrm{c}}-\mathrm{S}$ relation as earlier reported for oil-water system (Mirzaei and 889 Das 2007) as the micro-heterogeneities are abundant in oil reservoirs (Van Lingen et al. 890 1996; Pickup et al. 2005). A list of experimental methods, fluid and media 891 characteristics and various equipment applications by various authors in connection with $\mathrm{P}^{\mathrm{c}}-\mathrm{S}-\mathrm{K}_{\mathrm{r}}$ determination for $\mathrm{ScCO}_{2}$-brine system in the context of geological sequestration is shown in Table 2.

894

\subsection{Leakage risks and monitoring}

896

Risks of leakage of stored carbon dioxide portend serious dangers to the potable water aquifers that may lie along the escape paths. Also, on the earth's surface, living species are susceptible to $\mathrm{CO}_{2}$ inhalation while leakage through the ocean with consequent acidification poses harm to marine life. Technically, leaks could occur as results of gravity override together with viscous instability causing the carbon dioxide to move to the top of the injection layer bypassing large quantities of brine (Gasda 2008; Saripalli et al. 2001; Metz et al. 2005). If the caprock however has favourable pathways, the carbon dioxide could escape vertically compromising the intention of the process. The vertical buoyant pressure applied on the caprock by the carbon dioxide is as a result of difference in density between the formation waters and the carbon dioxide, and the thickness of the carbon dioxide plume accumulation.

907

Monitoring technologies are widely discussed in the literature. They are built upon the physico-chemical properties of the $\mathrm{CO}_{2}$-brine-rock system or the detection of the reaction by-products or even the coupled process effects such as micro-seismicity (Espinoza et al. 2011). Methods like electrical resistivity and wave propagation are most often employed in deep reservoir applications (Nakatsuka et al. 2010) while application of tracers like $\mathrm{SF}_{6}$ aid the monitoring of fluid movement. The monitoring methods should extend several hundred meters beyond the injection region to safely check the advancing plume of $\mathrm{CO}_{2}$. In addition, monitoring the deep region around the aquifers should be coupled with near surface and surface monitoring.

918 To this end, available technologies should be adequately utilised. These include: 919 electromagnetic techniques (Nakatsuka et al. 2010), temperature signals (Bielinski et al. 
920 2008) and infrared monitoring (Charpentier et al. 2009) that have been demonstrated

921 either in the laboratory or pilot applications for subsurface monitoring. Methods like 922 electromagnetic techniques utilise the wide gap between the dielectric permitivitties of $923 \mathrm{CO}_{2}$ and water to create contrast with reference the $\mathrm{CO}_{2}$ saturation in the domain. Non924 isothermal effects such as $\mathrm{CO}_{2}$ dissolution and change of phase are made use of in the 925 temperature signal method while the characteristic infrared wave absorption property of $926 \mathrm{CO}_{2}$ is harnessed in the infrared monitoring technique. Near surface monitoring is also 927 essential as stated before and this involves the analysis of near surface water, air and 928 soil samples on a regular basis as $\mathrm{CO}_{2}$ leaks can acidify the water and create 929 conspicuous contrast between the original and current soil and air compositions. On the 930 surface, the use of gravity method (Alnes et al. 2008) as $\mathrm{CO}_{2}$ is heavier than air and 931 lighter than water, remote sensing of air composition (Leuning et al. 2008) and surface 932 analysis of carbon content by Inelastic Neutron Scattering (INS) (Wielopolski and Mitra 933 2010) have been reported. Overall, monitoring protocols are essential for effectiveness 934 of success of geological sequestration of $\mathrm{CO}_{2}$.

935

\section{$936 \quad 7.0 \quad$ Concluding remarks}

937 To address the issues of climate change and the problems of global warming requires 938 meticulous scientific and engineering approaches. The current opinions favour geological sequestration option. Therefore, $\mathrm{scCO}_{2}$-brine-rock interactions together with the in situ processes and trapping mechanisms should be quantified accurately as they play significant roles in determining the efficiency and safety of these processes. . Out of many candidate sites, choosing an appropriate geological site requires optimizing the process functions relating to the media, fluid and operational characteristics. This is more so as these characteristics directly or indirectly affect the processes which determine safe $\mathrm{CO}_{2}$ storage, e.g., dissolution and structural trapping, reaction and mineral precipitation, etc. $\mathrm{CO}_{2}$ solubility is influenced by the porosity and pore size distribution (Emmanuel et al. 2010). So, developing the optimization protocols will aid the general practices in this regard. In relation to this, mathematical modelling and simulation tools have played significant roles, providing insightful predictions of the fate of the stored carbon and various processes including the trapping mechanisms. But, the site-specific indicators of $\mathrm{CO}_{2}$ leakage, and predictable compromise of reservoir integrity with the quantity and dynamics of $\mathrm{CO}_{2}$ in the reservoir are desired to be integrated in the system software with fully-coupled geochemical, fluid-fluid-solid,

954 hydrogeological, physical and chemo-physical conditions. Such indicator or factor 
955 should consider the impact of man-made leakage zone (see, e.g., (Humez et al. 2011; 956 Tao and Bryant 2014)) as well as natural-leakage zone (see, e.g., (Schwartz 2014)). 957 Affordable and commercial availability of the software products will drive research and 958 field developments.

959

960 As a special kind of two-phase flow system, $\mathrm{P}^{\mathrm{c}}-\mathrm{S}-\mathrm{K}_{\mathrm{r}}$ relationships for $\mathrm{scCO}_{2}$-brine961 rock system are important in the modelling and analysis of the sequestration operations. 962 But, the list of available experimental publications is far from sufficient especially when 963 viewed from possible factors that can affect $P^{c}-S-K_{r}$ relationships from closely 964 related process as encountered in the studies of oil recovery, oil spill remediation, 965 contaminant transport and so on. Wettability of the medium is shown to be responsible 966 for the irregularity in the pattern of $P^{c}-S-K_{r}$ relationships (Plug and Bruining 2007) with the possibility of in situ alteration in media wettability. This needs further investigation in order to keep the function applicable in the modelling and prediction of sequestration process and storage safety.

970

971 Most of the $\mathrm{P}^{c}-\mathrm{S}-\mathrm{K}_{\mathrm{r}}$ relationships reported are related to quasi-static or equilibrium 972 conditions. The dynamic behaviour of the system particularly at the immediate time 973 following injection prior to the attainment of equilibrium needs to be better understood. 974 In this regards, the difference in the quasi static or dynamically measured $\mathrm{P}^{\mathrm{c}}-\mathrm{S}-\mathrm{K}_{\mathrm{r}}$ 975 relationships will be of interests. Researchers of multiphase flow had dedicated past 976 decades to the study of various dynamic effects in system properties of multiphase flow. 977 Part of the investigations dwelled largely on the saturation-rate dependency of the 978 system properties and a number of publications had resulted (Hassanizadeh and Gray 979 1993; Das et al. 2007; Mirzaei and Das 2007; Hanspal and Das 2012; Dahle et al. 2005; 980 Goel and O'Carroll 2011; Das and Mirzaei 2013). Particularly for $\mathrm{P}^{\mathrm{c}}-\mathrm{S}$ relationships, 981 the dynamic coefficient, $\mathrm{T}$, used in quantifying this phenomenon has been said to be 982 dependent on media permeability (Mirzaei and Das 2007; Tian et al. 2012; Hanspal and 983 Das 2012; Dahle et al. 2005), microheterogeneity (Mirzaei and Das 2007), fluid 984 properties (Das et al. 2007; Goel and O'Carroll 2011), scale of observation (Dahle et al. 985 2005; Bottero et al. 2006 ; Bottero et al. 2011; Nordbotten et al. 2007), etc. Though, the 986 observations and reports were made largely in relation to oil-water system, investigating 987 the same effects for the rock- $\mathrm{SCO}_{2}$-brine system will broaden the present state of 
988 study while improving the applicability and integrity of $\mathrm{P}^{\mathrm{c}}-\mathrm{S}-\mathrm{K}_{\mathrm{r}}$ relationships as a

989 modelling function for the rock- $\mathrm{SCCO}_{2}$-brine system.

990

991 For example, different media permeabilities are encountered and hardly can two porous 992 media share the same permeability even at a contiguous sediment. A look at Table 2 993 reveals this reality as each experiment has different media permeability unique to it. 994 Even within an aquifer or reservoir, media anisotropy may be assumed but the reality 995 dictates otherwise (Pickup et al. 2005; Nordbotten et al. 2007; Aggelopoulos and 996 Tsakiroglou 2008). Micro-heterogeneities are another closely related property of the 997 porous media. These are abundant in the reservoir (Van Lingen et al. 1996; Pickup et al. 998 2005) and they affect the micro and macro scale quantity of the system variables while $999 \mathrm{~T}$ is said to increase with its intensity (Mirzaei and Das 2007). Aquifer or reservoir 1000 exhibits these properties or characteristics with few exceptions and are worth 1001 investigating in the context of carbon sequestration, especially the way they affect the $1002 \mathrm{P}^{\mathrm{c}}-\mathrm{S}-\mathrm{K}_{\mathrm{r}}$ relationships.

1003

1004 To determine $\mathrm{P}^{\mathrm{c}}-\mathrm{S}$ relationships for two-phase flow in any aquifer or reservoir, 1005 pressures in both phases need to be measured separately and saturation 1006 simultaneously determined. From the literature discussed in this review, it seems that 1007 the common laboratory measurement methods used for determining the $\mathrm{P}^{\mathrm{c}}-\mathrm{S}$ 1008 parameters for $\mathrm{scCO}_{2}$-brine/water system can be better described as pressure drop 1009 across the domain to get the $\mathrm{P}^{\mathrm{c}}$ and the measurement of the outflow water or brine for the saturation. An advanced in situ saturation measurement method was presented by Pini et al. (2012) using a medical X-ray CT scanning instrument with good resolution. This has the additional ability to determine the sample porosity. But the cost of this instrument and technicalities may pose challenges to many promising investigations. To overcome this, instruments like time domain reflectometer (TDR) can be recommended. They had been variously used to obtain in situ saturation measurement for decades (Das and Mirzaei 2013; Goel and O'Carroll 2011; Camps-Roach et al. 2010; Topp et al. 1984). Most of these experiments were conducted for oil-water and air-water systems mostly at near ambient condition but the instrument is still easily adaptable to the supercritical condition of carbon sequestration. The TDR probe has the capacity to determine the bulk electrical conductivity of the system in addition to the dielectric constant used in determining water saturation. 
Table 2: Typical $\mathrm{P}^{\mathrm{C}}-\mathrm{S}-\mathrm{K}_{\mathrm{r}}$ experiments for $\mathrm{ScCO}_{2}$-brine/water system in the literature (D: diameter L: Length)

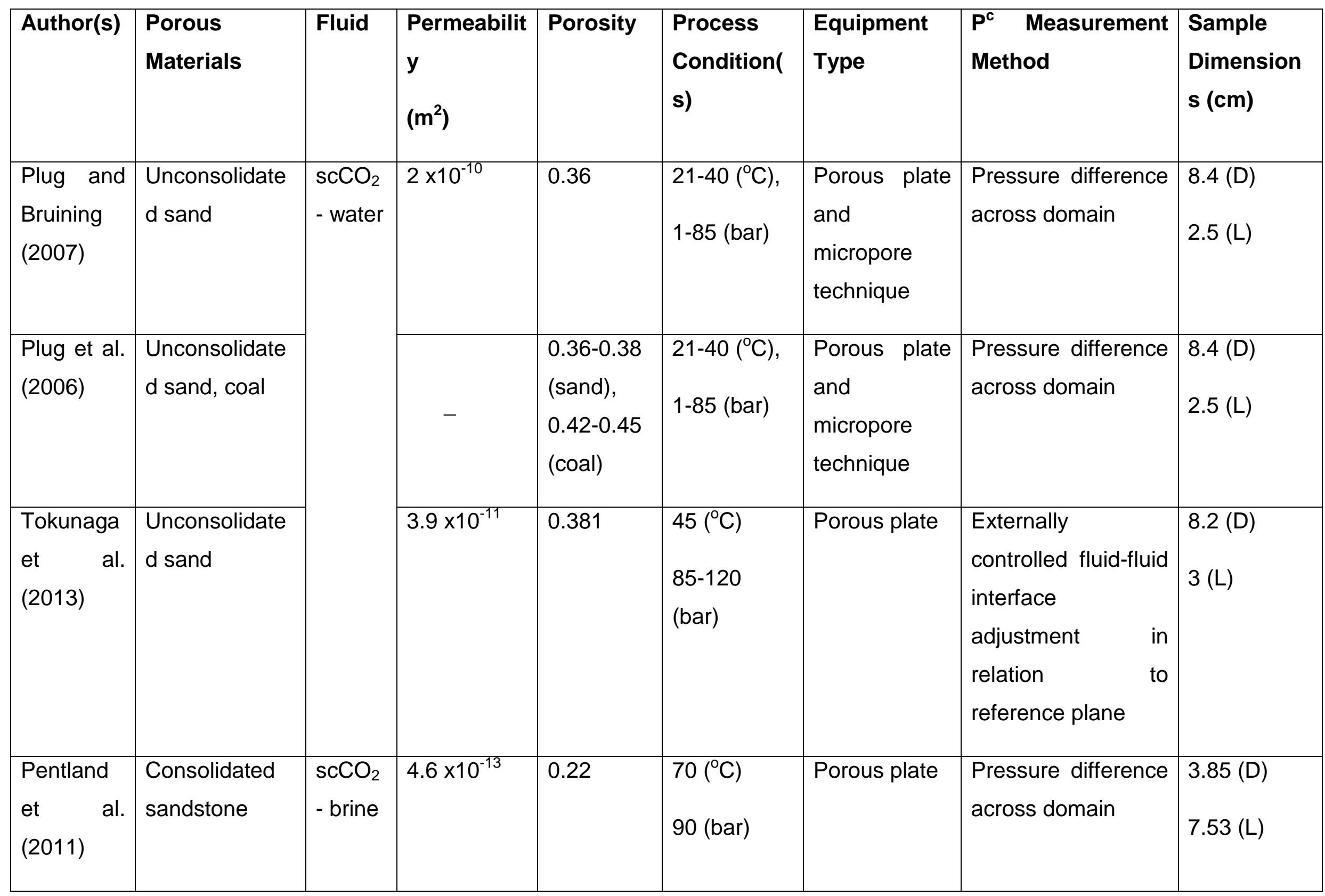




\begin{tabular}{|l|l|l|l|l|l|l|l|l|}
\hline $\begin{array}{l}\text { Pini et al. } \\
(2012)\end{array}$ & & & $2.7 \times 10^{-13}$ & 19.5 & $25-50\left({ }^{\circ} \mathrm{C}\right)$ & $\begin{array}{l}\text { Modified } \\
\text { porous plate }\end{array}$ & $9(\mathrm{D})$ \\
\hline
\end{tabular}


1024 It has been argued that external measurement of capillary pressure loses 1025 significance near residual saturation (Morrow and Harris 1965; Bottero 2009) as the 1026 non-wetting phase pressure dominates at this period when the wetting phase 1027 experience disconnectivity and thus making the measured wetting phase pressure 1028 appear larger. This makes the $\mathrm{P}^{c}$ smaller than supposed. But, the challenges of in situ phase pressure measurement are not simple, considering the high pressure and above ambient temperature of the supercritical $\mathrm{CO}_{2}$. At this state, most of the semi permeable membranes used by many authors (Das and Mirzaei 2012; Bottero et al. 2011; Hou et al. 2012) or porous ceramic discs (Camps-Roach et al. 2010; Goel and O'Carroll 2011) employed in oil-water or air-water systems will fail to distinguish any phase under supercritical condition as they were designed to operate under ambient conditions. However, there is hope in some of the metallic materials recently used by some authors under similar conditions even though they were not used to measure phase pressures. For example, C276 Hastelloy porous plate used by Tokunaga et al. (2013) and aluminium silicate by Pentland (2011) were described as semi permeable hydrophobic and hydrophilic discs, respectively under the supercritical conditions. Many other materials may still be available from membrane manufacturers to achieve this aim.

1043 The effect of scale on dynamic effect in $\mathrm{P}^{\mathrm{C}}-\mathrm{S}-\mathrm{K}_{\mathrm{r}}$ relationships is also well reported 1044 (Dahle et al. 2005; Bottero et al. 2011; Camps-Roach et al. 2010). Most of the experiments available for $\mathrm{scCO}_{2}$-brine-rock system are, at most, at the core scale 1046 size. How these relationships vary with size of the aquifer or field scale will be of great importance in the complete assessment of the factors affecting the $\mathrm{P}^{\mathrm{c}}-\mathrm{S}-\mathrm{K}_{\mathrm{r}}$ functions and will improve the versatility of their applications. The following bullet points will help to emphasis some suggestions based on this review:

- There are needs for experimental investigations of the effects of media characteristics e.g., domain scale, on the $\mathrm{P}^{\mathrm{c}}-\mathrm{S}-\mathrm{K}_{\mathrm{r}}$ relationships for $\mathrm{scCO}_{2}$ brine system at conditions applicable to geological carbon sequestration.

- To promote our understanding of caprock integrity, investigations of the pore size distribution on relative permeability of $\mathrm{CO}_{2}$ needs to be made clearer in 
conjunction with interfacial tension of the $\mathrm{scCO}_{2}$-brine system. For example, one may ask, 'how does the combination affect the entry pressure of the caprock?' Such investigations need to be conducted in the context of pressure, temperature, salt concentration, cation valence that are known to influence the interfacial tension. Contributions of the long-time mineral precipitation to change in salinity, combinations of cation valences and their effects on the above parameters will be very enlightening.

- Use of surfactants to curtail migration of $\mathrm{scCO}_{2}$ in saline aquifer and promote residual trapping will deserve future investigations, e.g., can surfactants check viscous and capillary fingerings in $\mathrm{ScCO}_{2}$-brine-rock systems? There are many works on the use of surfactant and $\mathrm{CO}_{2}$ in literature which are related to enhanced oil recovery (EOR).

- Inclusion of leakage parameters on a site-specific basis in the modelling and simulation of the system should be encouraged.

- The dynamic capillary pressure effects for the $\mathrm{P}^{\mathrm{c}}-\mathrm{S}-\mathrm{K}_{\mathrm{r}}$ relationships should be investigated in relation to $\mathrm{scCO}_{2}$-brine-rock system and these relationships should be incorporated in the relevant simulators for the geological carbon sequestration.

- The wettability alteration and the caprock integrity from the perspective of the alternation of the $\mathrm{scCO}_{2}$-brine-rock system conditions from neutrality to acidity and alkalinity as a result chemical complexation and mineral dissolution deserve more investigations. As different cationic valences change the interfacial tensions, how do similar changes in the subsurface conditions affect the wettability? This will be an important question to answer in future investigations.

- How continuous or intermittent injection and its rates influence residual trapping of injected $\mathrm{CO}_{2}$ will be a subject of interesting investigations.

- Cheap and simple $\mathrm{CO}_{2}$ leakage detection system should be developed for common household to be used for the independent assessment of $\mathrm{CO}_{2}$ gas accumulation, especially for residents closer to transport pipeline or geosequestration sites. 


\section{References}

1089

1090

1091

1092

1093

1094

1095

1096

1097

1098

1099

1100

1101

1102

1103

1104

1105

1106

1107

1108

1109

1110

1111

1112

Abu-Khader, M.M., 2006. Recent Progress in $\mathrm{CO}_{2}$ Capture/Sequestration: A Review. Energy Sources, Part A: Recovery, Utilization, and Environmental Effects, 28(14), pp.1261-1279.

Aggelopoulos, C. A., Robin, M., Perfetti, E. and Vizika, O., 2010. $\mathrm{CO}_{2} / \mathrm{CaCl}_{2}$ solution interfacial tensions under $\mathrm{CO} 2$ geological storage conditions: Influence of cation valence on interfacial tension. Advances in Water Resources, 33(6), pp.691697.

Aggelopoulos, C. A. and Tsakiroglou, C.D., 2008. The effect of micro-heterogeneity and capillary number on capillary pressure and relative permeability curves of soils. Geoderma, 148(1), pp.25-34.

Alabi, O.O., 2011. Fluid Flow in Homogeneous and Heterogeneous Porous Media. Electronic Journal of Geotechnical Engineering, 16.

Algive, L., Bekri, S., Vizika-kavvadias, O., 2009. Reactive pore network modeling dedicated to the determination of the petrophysical property changes while injecting $\mathrm{CO}_{2}$. In SPE Annual Technical conference and Exhibition.

Alnes, H., Eiken, O. and Stenvold, T., 2008. Monitoring gas production and CO 2 injection at the Sleipner field using time-lapse gravimetry. Geophysics, 73(6), pp.WA155-WA161.

Anderson, W., 1987. Wettability Literature Survey Part 5: The Effects Of Wettability On Relative Permeability. Journal of Petroleum Technology, 39(11), pp.14531468.

Babchin, A., Brailovsky, I., Gordon, P. and Sivashinsky, G., 2008. Fingering instability in immiscible displacement. Physical Review-Series E-, 77(2), 026301.

Bear, J., 2013. Dynamics of fluids in porous media, Courier Dover Publications. 
1113 Beni, A.N., Kühn, M., Meyer, R. and Clauser, C., 2012. Numerical modeling of a potential geological $\mathrm{CO}_{2}$ sequestration site at Minden (Germany). Environmental Modeling \& Assessment, 17(4), pp.337-351.

1116

Bennion, B. and Bachu, S., 2008. and imbibition relative permeability relationships for supercritical $\mathrm{CO}_{2} /$ brine and $\mathrm{H} 2 \mathrm{~S} /$ brine systems in intergranular sandstone, carbonate, shale, and anhydrite rocks. SPE Reservoir Evaluation \& Engineering, 11(3).

Benson, S.M. and Cole, D.R., 2008. $\mathrm{CO}_{2}$ sequestration in deep sedimentary formations. Elements, 4(5), pp.325-331.

Bentham, M., 2006. An assessment of carbon sequestration potential in the UK-Southern North Sea case study. Tyndall Centre for Climate Change Research and British Geological Survey. Keyworth, Nottingham, UK: Kingsley Dunham Centre.

Berg, S. and Ott, $\mathrm{H} ., 2012$. Stability of $\mathrm{CO}_{2}$-brine immiscible displacement. International Journal of Greenhouse Gas Control, 11, pp.188-203.

Bickle, M., Chadwick, A., Huppert, H. E., Hallworth, M. and Lyle, S., 2007. Modelling carbon dioxide accumulation at Sleipner: Implications for underground carbon storage. Earth and Planetary Science Letters, 255(1), pp.164-176.

Bielinski, A., Kopp, A., Schütt, $\mathrm{H}$. and Class, $\mathrm{H}$., 2008. Monitoring of $\mathrm{CO}_{2}$ plumes during storage in geological formations using temperature signals: Numerical investigation. International Journal of Greenhouse Gas Control, 2(3), pp.319328.

Bissell, RC, Vasco DW, Atbi M, Hamdani M, Okwelegbe M, Goldwater MH., 2011. A full field simulation of the in Salah gas production and $\mathrm{CO}_{2}$ storage project using a coupled geo-mechanical and thermal fluid flow simulator. Energy Procedia, 4, pp.3290-3297.

Bottero, S., Hassanizadeh, S. M., Kleingeld, P. J. and Bezuijen, A., 2006. Experimental study of dynamic capillary pressure effect in two-phase flow in 
porous media. In Proceedings of the XVI International Conference on Computational Methods in Water Resources (CMWR), Copenhagen, Denmark (pp. 18-22).

1144 Bottero, S., Hassanizadeh, S. M., Kleingeld, P. J., and Heimovaara, T. J., 2011. Nonequilibrium capillarity effects in two-phase flow through porous media at different scales. Water Resources Research, 47(10).

Bottero, S., 2009. Advances in the Theory of Capillarity in Porous Media. Universiteit Utrecht.

Bottero, S., Hassanizadeh, S. M. and Kleingeld, P. J., 2011. From Local Measurements to an Upscaled Capillary Pressure-Saturation Curve. Transport in Porous Media, 88(2), pp.271-291.

Bower, K.M. and Zyvoloski, G., 1997. A numerical model for thermo-hydro1153 mechanical coupling in fractured rock. International Journal of Rock Mechanics and Mining Sciences, 34(8), pp.1201-1211.

Brooks, R. and Corey, A., 1964. Hydraulic Properties of Porous Media. Hydrology 1156 Papers. Colorado State University.

Burdine, N., 1953. Relative permeability calculations from pore size distribution data. Journal of Petroleum Technology, 5(03), pp.71-78.

Burdine, N.T., Gournay, L.S. and Reichertz, P.P., 1950. No Title"Pore Size Distribution of Petroleum Reservoir Rocks." Trans. AIME, 198, pp.195-204.

1161 Camps-Roach, G., O'Carroll, D. M., Newson, T. A., Sakaki, T. and Illangasekare, T. H., 2010. Experimental investigation of dynamic effects in capillary pressure: Grain size dependency and upscaling. Water Resources Research, 46(8).

1164 Chadwick, A., Arts, R., Bernstone, C. and May, F., 2008. Best Practice for the 1165 Storage of $\mathrm{CO}_{2}$ in Saline Aquifers-Observations and Guidelines from the SACS and CO2STORE projects, 
1167 Chalbaud, C., Robin, M., Lombard, J., Bertin, H. and Egermann, P., 2010. Brine / CO 2 Interfacial Properties and Effects on $\mathrm{CO}_{2}$ Storage in Deep Saline Aquifers.

Chang, Y.-B., Coats, B. and Nolen, J., 1998. A Compositional Model for $\mathrm{CO}_{2}$ Floods Including $\mathrm{CO}_{2}$ Solubility in Water. SPE Reservoir Evaluation \& Engineering, 1(2), pp.155-160.

Charpentier, F. et al., 2009. Infrared monitoring of underground $\mathrm{CO}_{2}$ storage using chalcogenide glass fibers. Optical Materials, 31(3), pp.496-500.

Chiquet, P., Broseta, D. and Thibeau, S., 2007. Wettability alteration of caprock minerals by carbon dioxide. Geofluids, 7(2), pp.112-122.

Chun, B.-S. and Wilkinson, G.T., 1995. Interfacial tension in high-pressure carbon 1178 dioxide mixtures. Industrial \& Engineering Chemistry Research, 34(12), pp.4371-4377.

Class, H., Ebigbo, A., Helmig, R., Dahle, H. K., Nordbotten, J. M., Celia, M. A., and Wei, L., 2009. A benchmark study on problems related to $\mathrm{CO}_{2}$ storage in geologic formations. Computational Geosciences, 13(4), pp.409-434.

1183 Dahle, Helge K., Celia, M. a. and Majid Hassanizadeh, S., 2005. Bundle-of-Tubes 1184 Model for Calculating Dynamic Effects in the Capillary-Pressure- Saturation Relationship. Transport in Porous Media, 58(1-2), pp.5-22.

Das, DB. SM Hassanizadeh, BE Rotter, B Ataie-Ashtiani (2004). A numerical study of micro-heterogeneity effects on upscaled properties of two-phase flow in porous media. Transport in porous media 56 (3), 329-350

Das, D.B., Gauldie, R. and Mirzaei, M., 2007. Dynamic Effects for Two-Phase Flow in Porous Media : Fluid Property Effects. AIChE , 53(10), pp. 2505-2520.

1191 Das, D.B. and Mirzaei, M., 2012. Dynamic effects in capillary pressure relationships for two-phase flow in porous media: Experiments and numerical analyses. AlChE Journal, 58(12), pp.3891-3903. 
1205

1206

1207

1208 1209

1210

1211

1212

1213

1214

1215

1216

1217 Emmanuel, S., Ague, J.J. and Walderhaug, O., 2010. Interfacial energy effects and 1218

Das, D.B. and Mirzaei, M., 2013. Experimental measurement of dynamic effect in capillary pressure relationship for two-phase flow in weakly layered porous media. AIChE Journal, 59(5), pp.1723-1734.

Das, D.B., Mirzaei, M. and Widdows, N., 2006. Non-uniqueness in capillary pressure-saturation-relative permeability relationships for two-phase flow in porous media: Interplay between intensity and distribution of random microheterogeneities. Chemical Engineering Science, 61(20), pp.6786-6803.

Dodds, W.S., Stutzman, L.F. and Sollami, B.J., 1956. Carbon dioxide solubility in water.Chemical \& Engineering Data Series, 1(1), pp.92-95.

DOE, 2010. Fossil. Available at: http://www.energy.gov/science-innovation/energysources/fossil.

Dollimore, D. and Heal, G.R., 1964. An improved method for the calculation of pore size distribution from adsorption data. Journal of Applied Chemistry, 14(3), pp.109-114.

Doughty, C., 2007. Modeling geologic storage of carbon dioxide: Comparison of nonhysteretic and hysteretic characteristic curves. Energy Conversion and Management, 48(6), pp.1768-1781.

Drever, J.I. and Stillings, L.L., 1997. The role of organic acids in mineral weathering. Colloids and Surfaces A: Physicochemical and Engineering Aspects, 120(1), pp.167-181.

Duan, Z. and Sun, R., 2003. An improved model calculating $\mathrm{CO}_{2}$ solubility in pure water and aqueous $\mathrm{NaCl}$ solutions from 273 to $533 \mathrm{~K}$ and from 0 to 2000 bar. Chemical Geology, 193(3), pp.257-271. the evolution of pore size distributions during quartz precipitation in sandstone. Geochimica et Cosmochimica Acta, 74(12), pp.3539-3552. 
1220 Espinoza, D. N., Kim, S.H. and Santamarina, J. C., 2011. $\mathrm{CO}_{2}$ geological storage Geotechnical implications. KSCE Journal of Civil Engineering, 15(4), pp.707719.

1223

1224

1225

1226

1228

1229

1230

1231

1232

1233

1234 1235

1236

1238

1239

1240

1241

1242

1243

1244 1245

Espinoza, D. Nicolas and Santamarina, J. Carlos, 2010. Water- $\mathrm{CO}_{2}$-mineral systems: Interfacial tension, contact angle, and diffusion-Implications to $\mathrm{CO}_{2}$ geological storage. Water Resources Research, 46(7).

Farajzadeh, R., 2009. Enhanced transport phenomena in $\mathrm{CO}_{2}$ sequestration and CO2 EOR, PhD thesis, Technical University Delft, The Netherlands.

Fleury, M. et al., 2010. Petrophysical measurements for $\mathrm{CO}_{2}$ storage: application to the Ketzin site. The Society of Core Analysts, SCA News SCA2010-06, 22, pp.1-12.

Fujii, T., Gautier, S, Gland, N., Boulin, P., Norden, B., Schmidt-Hattenberger, C., 2010. Sorption Characteristics of $\mathrm{CO}_{2}$ on Rocks and Minerals in Storing $\mathrm{CO}_{2}$ Processes. Natural Resources (2158-706X), 1(1).

Garcia, J.E., 2001. Density of aqueous solutions of $\mathrm{CO}_{2}$. Available at: http://escholarship.org/uc/item/ 6dn022hb.

Gasda, S.E., 2008. Numerical Models for Evaluating $\mathrm{CO}_{2}$ Storage in Deep, Saline Aquifers: Leaky Wells and Large-Scale Geological Features. Princeton University.

Gaus, I., Azaroual, M. and Czernichowski-Lauriol, I., 2005. Reactive transport modelling of the impact of $\mathrm{CO}_{2}$ injection on the clayey cap rock at Sleipner (North Sea). Chemical Geology, 217(3), pp.319-337.

Goel, G. and O'Carroll, D.M., 2011. Experimental investigation of nonequilibrium capillarity effects: Fluid viscosity effects. Water Resources Research, 47(9).

Gunter, W.D. et al., 2009. Heartland Area Redwater reef saline aquifer $\mathrm{CO}_{2}$ storage project. Energy Procedia, 1(1), pp.3943-3950. 
Hansen, J. et al., 2008. Target atmospheric $\mathrm{CO}_{2}$ : Where should humanity aim? arXiv preprint arXiv:0804.1126.

Hanspal, N. and Das, D., 2012. Dynamic effects on capillary pressure-saturation relationships for two-phase porous flow: Implications of temperature. AIChE Journal, 00(0), pp.1-15.

Hassanizadeh, S Majid and Gray, W.G., 1993. Thermodynamic basis of capillary pressure in porous media. Water Resources Research, 29(10), pp.3389-3405.

Homsy, G.M., 1987. Viscous fingering in porous media. Annual Review of Fluid Mechanics, 19(1), pp.271-311.

Hou, L., Chen, L., Kibbey, T. C. G. and Street, W. B., 2012. Dynamic capillary effects in a small-volume unsaturated porous medium: Implications of sensor response and gas pressure gradients for understanding system dependencies, Water Resources Research, 48(11).

Houghton, J.T., Ding, Y.D.J.G., Griggs, D. J., Noguer, M., van der LINDEN, P. J., Dai, X., Maskell, K., and Johnson, C. A., 2001. Climate change 2001: the scientific basis, Cambridge university press Cambridge.

Huh, C., Kang, S. G., Hong, S., Choi, J. S., Baek, J. H., Lee, C. S., and Lee, J. S., 2009. $\mathrm{CO}_{2}$ storage in marine geological structure: A review of latest progress and its application in Korea. Energy Procedia, 1(1), pp.3993-4000.

Humez, P., Audigane, P., Lions, J., Chiaberge, C., and Bellenfant, G., 2011. Modeling of $\mathrm{CO}_{2}$ leakage up through an abandoned well from deep saline aquifer to shallow fresh groundwaters. Transport in porous media, 90(1), pp.153-181.

Huo, D. and Gong, B., 2010. Discrete Modeling and Simulation on Potential Leakage through Fractures in $\mathrm{CO}_{2}$ Sequestration. In SPE Annual Technical Conference and Exhibition. 
1272 Joekar-Niasar, V. and Majid Hassanizadeh, S., 2011. Effect of fluids properties on non-equilibrium capillarity effects: Dynamic pore-network modeling. International Journal of Multiphase Flow, 37(2), pp.198-214.

1275

Juanes, R., Spiteri, E. J., Orr, F. M. and Blunt, M. J., 2006. Impact of relative 1276 permeability hysteresis on geological $\mathrm{CO}_{2}$ storage. Water Resources Research, 42(12).

1278

Karl, T.R., Melillo, J.M. and Peterson, T.C., 2009. Global climate change impacts in 1279 the United States, Cambridge University Press.

1280

1281

1282

1283

1284

1285

1286

1287

1288

1289

1290

1291

1292

1293

1294

1295

1296

1297

Khudaida, K and Das, DB (2014). A numerical study of capillary pressure - saturation relationship for supercritical carbon dioxide (CO2) injection in deep saline aquifer. Chemical Engineering Research and Design, DOI: 10.1016/j.cherd.2014.04.020 (in press).

Kopp, A, Class, $\mathrm{H}$ and Helmig, $\mathrm{R}, 2009$. Investigations on $\mathrm{CO}_{2}$ storage capacity in saline aquifers: Part 1. Dimensional analysis of flow processes and reservoir characteristics. International Journal of Greenhouse Gas Control, 3(3), pp.263276.

Kvamme, B., Kuznetsova, T., Hebach, A., Oberhof, A., and Lunde, E., 2007. Measurements and modelling of interfacial tension for water+carbon dioxide systems at elevated pressures. Computational Materials Science, 38(3), pp.506-513.

Lenormand, R., Delaplace, P. and Schmitz, P., 1998. Can we really measure the relative permeabilities using the micropore membrane method? Journal of Petroleum Science and Engineering, 19(1-2), pp.93-102.

Lenormand, R., Touboul, E. and Zarcone, C., 1988. Numerical models and experiments on immiscible displacements in porous media. J. Fluid Mech. (1988),, 189(C), pp.165-187. 
1298

1299

1300

1301

1302

1303

1304

1305

1306

1307

1308

1309

1310

1311

1312

1313

1314

1315

1316

1317

1318

1319

1320

1321

1322

1323

Leuning, R., Etheridge, D., Luhar, A. and Dunse, B., 2008. Atmospheric monitoring and verification technologies for $\mathrm{CO}_{2}$ geosequestration. International Journal of Greenhouse Gas Control, 2(3), pp.401-414.

Li, L., Peters, C.A. and Celia, M.A., 2006. Upscaling geochemical reaction rates using pore-scale network modeling. Advances in water resources, 29(9), pp.1351-1370.

Van Lingen, P., Bruining, J. and C.P.J.W., V., 1996. Capillary Entrapment Caused by Small-Scale Wettability Heterogeneities. SPE Reservoir Engineering, 11(2), pp.93-100.

Marland, G. and Rotty, R.M., 1984. Carbon dioxide emissions from fossil fuels: A procedure for estimation and results for 1950--1982. Tellus B, 36(4), pp.232261.

Metz, B., Davidson, O., de Coninck, H., Loos, M., and Meyer, L., 2005. IPCC special report on carbon dioxide capture and storage, Intergovernmental Panel on Climate Change, Geneva (Switzerland). Working Group III. Cambridge University Press.

Van Meurs, P., 1957. The use of transparent three-dimensional models for studying the mechanism of flow processes in oil reservoirs. In: SPE Annual Technical Conference and Exhibition, Anaheim, CA, vol. 210, pp. 295-301

Michael, K., Golab, A., Shulakova, V., Ennis-King, J., Allinson, G., Sharma, S., and Aiken, T., 2010. Geological storage of $\mathrm{CO}_{2}$ in saline aquifers-A review of the experience from existing storage operations. International Journal of Greenhouse Gas Control, 4(4), pp.659-667.

Mirzaei, M. and Das, D.B., 2007. Dynamic effects in capillary pressure-saturations relationships for two-phase flow in 3D porous media: Implications of microheterogeneities. Chemical Engineering Science, 62(7), pp.1927-1947. 
Mirzaei, M and Das, DB (2013). Experimental investigation of hysteretic dynamic effect in capillary pressure-saturation relationship for two-phase flow in porous media. AIChE Journal, 59(10), 3958-3974.

Morris, J. P., Hao, Y., Foxall, W. and McNab, W., 2011. In salah $\mathrm{CO}_{2}$ storage JIP: hydromechanical simulations of surface uplift due to $\mathrm{CO}_{2}$ injection at in salah. Energy Procedia, 4, pp.3269-3275.

Morris, J. P., Detwiler, R. L., Friedmann, S. J., Vorobiev, O. Y. and Hao, Y., 2011. The large-scale geomechanical and hydrogeological effects of multiple $\mathrm{CO}_{2}$ injection sites on formation stability. International Journal of Greenhouse Gas Control, 5(1), pp.69-74.

Morrow, N. and Harris, C., 1965. Capillary Equilibrium in Porous Materials. Society of Petroleum Engineers Journal, 5(1), pp.418-420.

Müller, N., 2011. Supercritical $\mathrm{CO}_{2}$-Brine Relative Permeability Experiments in Reservoir Rocks-Literature Review and Recommendations. Transport in Porous Media, 87(2), pp.367-383.

Kaveh, N.S, E.S.J. Rudolph, W.R. Rossen, P. van Hemert, and K.H.Wolf, Interfacial Tension and Contact Angle Determination in Water-sandstone Systems with Injection of Flue Gas and $\mathrm{CO}_{2}$. IOR 2013 - 17th European Symposium on Improved Oil Recovery St. Petersburg, Russia, 16-18 April 2013, (April 2013), pp.16-18.

Nakatsuka, Y. et al., 2010. Experimental study on $\mathrm{CO}_{2}$ monitoring and quantification of stored $\mathrm{CO}_{2}$ in saline formations using resistivity measurements. International Journal of Greenhouse Gas Control, 4(2), pp.209-216.

Nielsen, L.C., Bourg, I.C. and Sposito, G., 2012. Predicting $\mathrm{CO}_{2}$-water interfacial tension under pressure and temperature conditions of geologic $\mathrm{CO}_{2}$ storage. Geochimica et Cosmochimica Acta, 81, pp.28-38. 
1350 Nordbotten, J. M., Celia, M. a., Dahle, H. K. and Hassanizadeh, S. M., 2007. Interpretation of macroscale variables in Darcy's law. Water Resources Research, 43(8).

Nordbotten, J. M, Celia, M. A., Dahle, H. K. and Hassanizadeh, S. M., 2008. On the definition of macroscale pressure for multiphase flow in porous media. Water Resources Research, 44(6), pp.1-8.

Nordbotten, Jan Martin, Celia, M.A. and Bachu, S., 2005. Injection and storage of 1357 $\mathrm{CO}_{2}$ in deep saline aquifers: Analytical solution for $\mathrm{CO}_{2}$ plume evolution during injection. Transport in Porous media, 58(3), pp.339-360.

Olivella, S., Carrera, J., Gens, A. and Alonso, E., 1994. Nonisothermal multiphase flow of brine and gas through saline media. Transport in porous media, 15(3), pp.271-293.

Omambia, A.N. and Li, Y., 2010. Numeric modeling of carbon dioxide sequestration 1363

Ouakad, H.M., 2013. Modeling the $\mathrm{CO}_{2}$ Sequestration Convection Problem Using the Lattice Boltzmann Method. Mathematical Problems in Engineering, 2013, pp.1-10.

Ouellet, A., Bérard, T., Desroches, J., Frykman P., Welsh, P., Minton, J., Pamukcu, Y, Hurter, S., Schmidt-Hattenberger, C., 2011. Reservoir geomechanics for assessing containment in $\mathrm{CO}_{2}$ storage: A case study at Ketzin, Germany. Energy Procedia, 4, pp.3298-3305.

Ozgur, E. and Gumrah, F., 2009. Diffusive and Convective Mechanisms during $\mathrm{CO}_{2}$ Sequestration in Aquifers. Energy Sources, Part A, 31(8), pp.698-709.

1374 Pentland, C.H., 2011. Measurements of Non-wetting Phase Trapping in Porous 1375 Media. 2010(Awarded). 
1376

1377

1378

1379

1380

1381

1382

1383

1384

1385

1386

1387

1388

1389

1390

1391

1392

1393

1394

1395

1396

1397

1398

1399

1400

1401

1402

1403

Pentland, C., El-Maghraby, R., Iglauer, S. and Blunt, M. J., 2011. Measurements of the capillary trapping of super-critical carbon dioxide in Berea sandstone. Geophysical Research Letters, 38(6), pp.2007-2010.

Pickup, G.E., Stephen, K. D., Ma, J., Zhang, P. and Clark, J. D., 2005. Multi-Stage Upscaling: Selection of Suitable Methods. In D B Das \& S M Hassanizadeh, eds. Upscaling Multiphase Flow in Porous Media SE - 10. Springer Netherlands, pp. 191-216.

Pini, R., Krevor, S.C.M. and Benson, S.M., 2012. Capillary pressure and heterogeneity for the $\mathrm{CO}_{2}$ /water system in sandstone rocks at reservoir conditions. Advances in Water Resources, 38, pp.48-59.

Pistone, S., Stacey, R. and Horne, R., 2011. THE SIGNIFICANCE OF $\mathrm{CO}_{2}$ SOLUBILITY IN GEOTHERMAL RESERVOIRS. Proceedings, Thirty-Sixth Workshop on Geothermal Reservoir Engineering. Stanford University, Stanford, California, January 31 - February 2, 2011.

Plug, W.-J. and Bruining, J., 2007. Capillary pressure for the sand $-\mathrm{CO}_{2}-$ water system under various pressure conditions. Application to $\mathrm{CO}_{2}$ sequestration. Advances in Water Resources, 30(11), pp.2339-2353.

Plug, W-J, Mazumder, S. and Bruining, J, 2006. Capillary pressure and wettability behavior of the coal-water-carbon dioxide system at high pressures. International CBM ..., pp.1-15.

Preisig, M. and Prévost, J.H., 2011. Coupled multi-phase thermo-poromechanical effects. Case study: $\mathrm{CO}_{2}$ injection at In Salah, Algeria. International Journal of Greenhouse Gas Control, 5(4), pp.1055-1064.

Pruess, K, Bielinski , A, Ennis-King, J, Le Gallo, Y, Garcia, J, Jessen, K, Kovscek, T, Law, D H- S, Lichtner, P, Oldenburg, C, Pawar, R., Rutqvist, J, Steefel, C, Travis, B, Chin-Fu Tsang, White, S, and Tianfu., 2003. Code intercomparison builds confidence in numerical models for geologic disposal of $\mathrm{CO}_{2}$. In J. GALE \& Y. KAYA, eds. Proceedings of the 6th International Conference on 
1404

1405

1406

1407

1408

1409

1410

1411

1412

1413

1414

1415

1416

1417

1418

1419

1420

1421

1422

1423

1424

1425

1426

1427

1428

1429

1430

1431

1432

Greenhouse Gas Control Technologies, Kyoto, Japan, October, 2002. Oxford, UK: Pergamon.

Pruess, Karsten, Oldenburg, C.M. and Moridis, G.J., 1999. TOUGH2 User's Guide Version 2. Lawrence Berkeley National Laboratory.

Pusch G, May F, Bernstone C, Höllwart J, Lillie J, Mundhenk N, W.H., 2010. Common Features of Carbon Dioxide and underground Gas Storage (2). Oil Gas European Magazine, 36(3/4), pp.131-136.

Riaz, A. and Tchelepi, H.A., 2004. Linear stability analysis of immiscible two-phase flow in porous media with capillary dispersion and density variation. Physics of Fluids (1994-present), 16(12), pp.4727-4737.

Ritter, L.C. and Drake, R.L., 1945. Pore Size Distribution in Porous Materials. Industrial \& Engineering Chemistry Analytical Edition,17(12), pp. 782786.Rutqvist, J, Wu, Y.-S., Tsang, C.-F. and Bodvarsson, G., 2002. A modeling approach for analysis of coupled multiphase fluid flow, heat transfer, and deformation in fractured porous rock. International Journal of Rock Mechanics and Mining Sciences, 39(4), pp.429-442.

Rutqvist, J., 2011. Status of the TOUGH-FLAC simulator and recent applications related to coupled fluid flow and crustal deformations. Computers \& Geosciences, 37(6), pp.739-750.

Rutqvist, Jonny, 2012. The Geomechanics of $\mathrm{CO}_{2}$ Storage in Deep Sedimentary Formations. Geotechnical and Geological Engineering, 30(3), pp.525551.Saffman, P.G. and Taylor, G., 1958. The penetration of a fluid into a porous medium or Hele-Shaw cell containing a more viscous liquid. Proceedings of the Royal Society of London. Series A. Mathematical and Physical Sciences, 245(1242), pp.312-329.

Salimi, H., Wolf, K.-H. and Bruining, 2012. The influence of capillary pressure on the phase equilibrium of the CO2-water system: Application to carbon sequestration combined with geothermal energy. International Journal of Greenhouse Gas Control, 11, pp.S47-S66. 
1433

1434

1435

1436

1437

1438

1439

1440

1441

1442

1443

1444

1445

1446

1447

1448

1449

1450

1451

1452

1453

1454

1455

1456

1457

1458

1459

1460

Saraji, S., Goual, L., Piri, M. and Plancher, H., 2013. Wettability of supercritical carbon dioxide/water/quartz systems: simultaneous measurement of contact angle and interfacial tension at reservoir conditions. Langmuir: the ACS journal of surfaces and colloids, 29(23), pp.6856-6866.

Saripalli, K.P., Mcgrail, B.P. and White, Mark D, 2001. Modeling the sequestration of $\mathrm{CO}_{2}$ in deep geological formations. In First National Conference on Carbon Sequestration. pp. 1-19.

Schwartz, M.O., 2014. Modelling leakage and groundwater pollution in a hypothetical CO2 sequestration project. International Journal of Greenhouse Gas Control, 23, pp.72-85.

Seaton, N.A. and Walton, J.P.R.B., 1989. A new analysis method for the determination of the pore size distribution of porous carbons from nitrogen adsorption measurements. Carbon, 27(6), pp.853-861.

Shafrin, E.G. and Zisman, W.A., 1960. Constitutive relations in the wetting of low energy surfaces and the theory of the retraction method of preparing monolayers1. The Journal of Physical Chemistry, 64(5), pp.519-524.

Shojai Kaveh, N., Rudolph, E. S. J., Wolf, K.-H. A. A. and Ashrafizadeh, S. N., 2011. Wettability determination by contact angle measurements: hvbB coal-water system with injection of synthetic flue gas and $\mathrm{CO}_{2}$. Journal of colloid and interface science, 364(1), pp.237-47.

Shukla, R., Ranjith, P., Haque, A. and Choi, X., 2010. A review of studies on $\mathrm{CO}_{2}$ sequestration and caprock integrity. Fuel, 89(10), pp.2651-2664.Silin, D., Patzek, T. and Benson, S.M., 2008. A Model of Buoyancy-Driven Two-Phase Countercurrent Fluid Flow. Transport in Porous Media, 76(3), pp.449-469.

Singh, P., Cavanagh, A., Hansen, H., Nazarian, B., Iding, M., and Ringrose, 2010. Reservoir Modeling of $\mathrm{CO}_{2}$ Plume Behavior Calibrated Against Monitoring Data From Sleipner Norway. In SPE annual technical conference and exhibition, 1922 September, Florence, Italy 
1461

Solomon, S., Qin, D., Manning, M., Chen, Z., Marquis, M., Averyt, K B., Tignor, M., Miller, H., 2007. The physical science basis. Contribution of working group I to the fourth assessment report of the Intergovernmental Panel on Climate Change, pp.235-337.

Stanmore, B.R. and Gilot, P., 2005. Review-calcination and carbonation of limestone during thermal cycling for $\mathrm{CO}_{2}$ sequestration. Fuel Processing Technology, 86(16), pp.1707-1743Taku Ide, S., Jessen, Kristian and Orr Jr, F.M., 2007. Storage of $\mathrm{CO}_{2}$ in saline aquifers: Effects of gravity, viscous, and capillary forces on amount and timing of trapping. International Journal of Greenhouse Gas Control, 1(4), pp.481-491.

Tao, Q. and Bryant, S.L., 2014. Well permeability estimation and $\mathrm{CO}_{2}$ leakage rates. International Journal of Greenhouse Gas Control, 22, pp.77-87.Tiab, D. and Donaldson, E.C., 2004. Petrophyiscs: Theory and Practice of Measuring Reservoir Rock and Fluid Transport Properties 2nd ed., Oxford: Gulf Professional Publishing (Elsevier).

Tian, S., Lei , G., He, S. and Yang, L., 2012. Dynamic effect of capillary pressure in low permeability reservoirs. Petroleum Exploration and Development, 39(3), pp.405-411.

Tokunaga, T.K., Wan, J. Jung, J-W, Kim, T.K., Kim, Y., Dong, W., 2013. Capillary pressure and saturation relations for supercritical $\mathrm{CO}_{2}$ and brine in sand: Highpressure $P_{c} \quad\left(S_{w}\right)$ controller/meter measurements, and capillary scaling predictions. Water Resources Research.

Topp, G.C., Zebchuk, W. D., Davis, J. L., and Bailey, W. G., 1984. The measurement of soil water content using a portable TDR hand probe. Canadian Journal of Soil Science, 64(3), pp.313-321.

Tsang, Chin-Fu, Birkholzer, J. and Rutqvist, Jonny, 2007. A comparative review of hydrologic issues involved in geologic storage of $\mathrm{CO}_{2}$ and injection disposal of liquid waste. Environmental Geology, 54(8), pp.1723-1737. 
1489

1490

1491

1492

1493

1494

1495

1496

1497

1498

1499

1500

1501

1502

1503

1504

1505

1506

1507

1508

1509

1510

1511

1512

1513

1514

1515

Vilarrasa, V., Bolster, D., Olivella, S. and Carrera, J., 2010. Coupled hydromechanical modeling of $\mathrm{CO}_{2}$ sequestration in deep saline aquifers. International Journal of Greenhouse Gas Control, 4(6), pp.910-919.

Vinegar, H.J. and Waxman, M.H., 1987. In-situ method for determining pore size distribution, capillary pressure and permeability. U.S. Patent No. 4,644,283. Washington, DC: U.S. Patent and Trademark Office.

Virnovsky, G.A., Skjaeveland, S. M., Ingsoy, P., Norge, E. and Surdal, J., 1995. Steady-State Relative Permeability Measurements Corrected for Capillary Effects. SPE Journal, (3), pp.85-95.

Wang, S., Edwards, I.M. and Clarens, A.F., 2012. Wettability phenomena at the co2-brine--mineral interface: Implications for geologic carbon sequestration. Environmental science \& technology, 47(1), pp.234-241.

Wang, W. and Kolditz, O., 2007. Object-oriented finite element analysis of thermohydro-mechanical (THM) problems in porous media. International journal for numerical methods in engineering, 69(1), pp.162-201.

Wang, Y., Zhang, C., Wei, N., Oostrom, M., Wietsma, T., Li, X., Bonneville, A., 2013. Experimental study of crossover from capillary to viscous fingering for supercritical $\mathrm{CO}_{2}$-water displacement in a homogeneous pore network. Environmental science \& technology, 47(1), pp.212-8.

Water, M., Abaci, S., Whittaker, N., 2006. Relative permeability measurements for two phase flow in unconsolidated sands. Mine Water and the Environment, 26(2), pp.12-26.

White, D., Burrowes, G., Davis, T., Hajnal, Z., Hirsche, K., Hutcheon, I., Majer, E., Rostron, B., Whittaker, S., 2004. Greenhouse gas sequestration in abandoned oil reservoirs: The International Energy Agency Weyburn pilot project. GSA today, 14(7), pp.4-11.

White, M.D., 2002. Example Problem 9 Simulation of supercritical $\mathrm{CO}_{2}$ into a deep saline aquifer. , pp.1-12. Pacific Northwest Laboratory. 
1517

1518

1519

1520

1521

1522

1523

1524

1525

1526

1527

1528

1529

1530

1531

1532

1533

1534

1535

1536

1537

1538

1539

1540

1541 Yortsos, Y.C. and Hickernell, F.J., 1989. Linear stability of immiscible displacement 1542

White, M.D., McGrail, B. P., Gale, J. and Kaya, Y., 2003. Numerical Investigations of Multifluid Hydrodynamics During Injection of Supercritical $\mathrm{CO}_{2}$ into Porous Media,

White, Mark D and McGrail, B Peter, 2005. Stomp (subsurface transport over multiple phase) version 1.0 addendum: Eckechem equilibriumconservationkinetic equation chemistry and reactive transport. Pacific Northwest National Laboratory, PNNL-15482, Richland, Washington.

White, SP, Weir, G. and Kissling, W.M., 2001. Numerical simulation of $\mathrm{CO}_{2}$ sequestration in natural $\mathrm{CO} 2$ reservoirs on the Colorado Plateau. This volume, (64).

Wielopolski, L. and Mitra, S., 2010. Near-surface soil carbon detection for monitoring $\mathrm{CO}_{2}$ seepage from a geological reservoir. Environmental Earth Sciences, 60(2), pp.307-312.

Woods, E.G., Comer, A.G. and others, 1962. Saturation distribution and injection pressure for a radial gas-storage reservoir. Journal of Petroleum Technology, 14(12), pp.1-389.

Van Wunnik, J.N.M. and Wit, K., 1989. A simple analytical model of the growth of viscous fingers in heterogeneous porous media. In: 1st European Conference on the Mathematics of Oil Recovery. University of Cambridge

Xu, T., Sonnenthal, E., Spycher, N. and Pruess, K., 2006. TOUGHREACT-A simulation program for non-isothermal multiphase reactive geochemical transport in variably saturated geologic media: Applications to geothermal injectivity and $\mathrm{CO}_{2}$ geological sequestration. Computers \& Geosciences, 32(2), pp.145-165.

in porous media. SIAM Journal on Applied Mathematics, 49(3), pp.730-748. 
1543 Zahid, U., Lim, Y., Jung, J. and Han, C., 2011. $\mathrm{CO}_{2}$ geological storage: A review on 1544 present and future prospects. Korean Journal of Chemical Engineering, 28(3), 1545 pp.674-685.

1546 Zakkour, P. and Haines, M., 2007. Permitting issues for $\mathrm{CO}_{2}$ capture, transport and 1547 geological storage: A review of Europe, USA, Canada and Australia. 1548 International Journal of Greenhouse Gas Control, 1(1), pp.94-100.

1549 Zhang, C., Oostrom, M., Wietsma, T. W., Grate, J. W. and Warner, M. G., 2011. 1550 Influence of Viscous and Capillary Forces on Immiscible Fluid Displacement: 1551 Pore-Scale Experimental Study in a Water-Wet Micromodel Demonstrating 1552 Viscous and Capillary Fingering. Energy \& Fuels, 25(8), pp.3493-3505. 